\title{
The effects of omega-3 polyunsaturated fatty acids on AMPK activation and lipid metabolism in skeletal muscle
}

Myra Ellen Woodworth-Hobbs

West Virginia University

Follow this and additional works at: https://researchrepository.wvu.edu/etd

\section{Recommended Citation}

Woodworth-Hobbs, Myra Ellen, "The effects of omega-3 polyunsaturated fatty acids on AMPK activation and lipid metabolism in skeletal muscle" (2009). Graduate Theses, Dissertations, and Problem Reports. 2812.

https://researchrepository.wvu.edu/etd/2812

This Thesis is protected by copyright and/or related rights. It has been brought to you by the The Research Repository @ WVU with permission from the rights-holder(s). You are free to use this Thesis in any way that is permitted by the copyright and related rights legislation that applies to your use. For other uses you must obtain permission from the rights-holder(s) directly, unless additional rights are indicated by a Creative Commons license in the record and/ or on the work itself. This Thesis has been accepted for inclusion in WVU Graduate Theses, Dissertations, and Problem Reports collection by an authorized administrator of The Research Repository @ WVU. For more information, please contact researchrepository@mail.wvu.edu. 


\title{
The Effects of Omega-3 Polyunsaturated Fatty Acids on
}

\section{$\underline{\text { AMPK Activation and Lipid Metabolism in Skeletal Muscle }}$}

Myra Ellen Woodworth-Hobbs, B.S.

\author{
Thesis submitted to the School of Medicine \\ at West Virginia University \\ in partial fulfillment \\ of the requirements for the degree of \\ Master of Science \\ in \\ Exercise Physiology
}
Randall W. Bryner, Ed.D., Chair
Stephen E. Alway, Ph.D.
David L. Williamson, Ph.D.

Division of Exercise Physiology

\author{
Morgantown, West Virginia \\ 2009
}

Copyright 2009 Myra E. Woodworth-Hobbs

Keywords: obesity, cell culture, insulin signaling 


\section{ABSTRACT}

The Effects of Omega-3 Polyunsaturated Fatty Acids on AMPK Activation and Lipid Metabolism in Skeletal Muscle

Myra Woodworth-Hobbs

Intramyocellular lipid accumulation and low lipid oxidative capacity contribute to the formation of insulin resistance, but omega-3 polyunsaturated fatty acids (n-3 PUFA) are shown to attenuate insulin resistance caused by high levels of saturated fats. The AMP-activated protein kinase (AMPK) promotes lipid oxidation and oxidative gene expression, highlighting its possible role in promoting insulin sensitivity by reducing lipid content and improving oxidative capacity. This study evaluated the effects of n-3 PUFA on the AMPK pathway and alterations to lipid content, oxidative markers, and insulin signaling proteins in a muscle cell culture model, with the hypothesis that n-3 PUFA would attenuate the saturated fatty acid-induced increase in intramyocellular lipids and detriments to the AMPK pathway, oxidative markers, and insulin signaling. The findings confirm that n-3 PUFA both attenuate saturated fatty acid-induced increases in intramyocellular lipid content and normalize insulin signaling and oxidative metabolic markers, though independently of the AMPK signaling pathway. 


\section{TABLE OF CONTENTS}

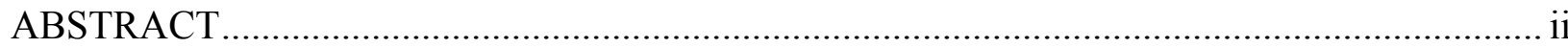

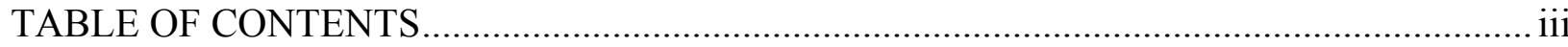

TABLE OF FIGURES ......................................................................................................

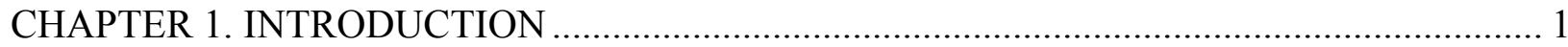

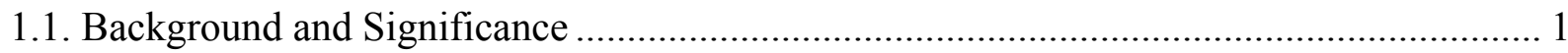

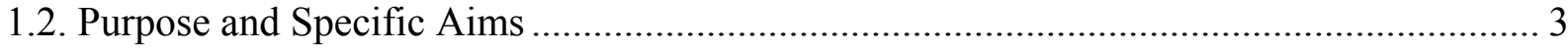

CHAPTER 2. REVIEW OF LITERATURE ................................................................... 5

2.1. Obesity contributes to the formation of insulin resistance and other chronic diseases ....... 5

2.2. Obesity is associated with intramyocellular triglyceride accumulation and formation of bioactive lipid species that contribute to insulin resistance ...................................................... 5

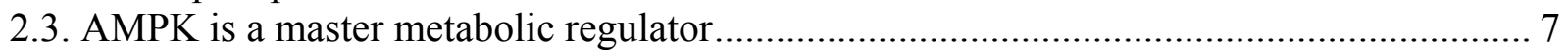

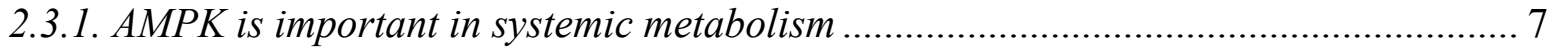

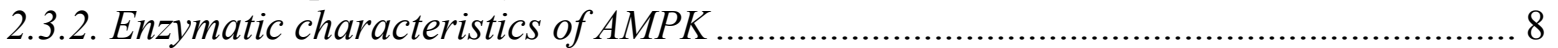

2.3.3. Allosteric modulation and phosphorylation of AMPK................................................. 8

2.3.4. AMPK contributes to acute and chronic lipid homeostasis ........................................ 9

2.3.5. Oxidative capacity is decreased with insulin resistance............................................ 11

2.3.6. Activation of AMPK enhances oxidative capacity .................................................. 12

2.4. Fatty acid treatments alter skeletal muscle AMPK...................................................... 12

2.4.1. Acute fatty acid treatments stimulate AMPK activity ............................................ 13

2.4.2. Long-term fatty acid treatments repress basal AMPK activity but may not affect the ability of AMPK to be chronically activated....................................................................... 13

2.5. Cellular effects of fatty acids depend on their structures................................................ 15

2.5.1. Saturated and unsaturated fatty acids differentially affect cellular metabolism ........ 15

2.5.2. Omega-3 polyunsaturated fatty acids enhance insulin sensitivity ............................. 15

2.6. Polyunsaturated fatty acids may alter skeletal muscle AMPK to improve insulin

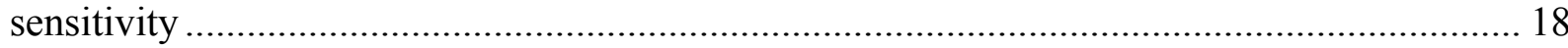

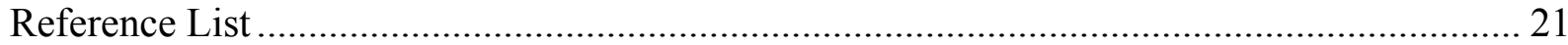

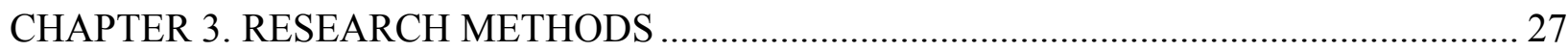

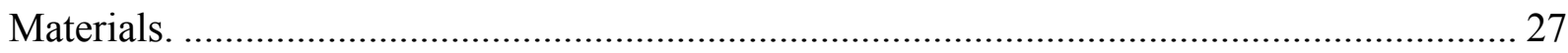

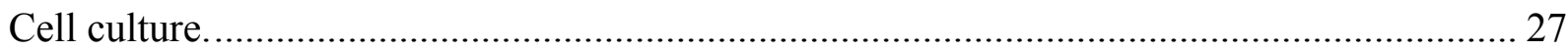

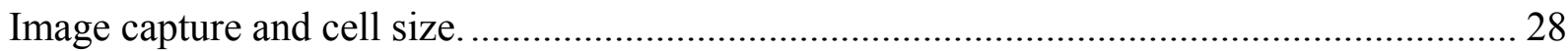

Evaluation of phosphorylated and total proteins. ……….................................................. 28

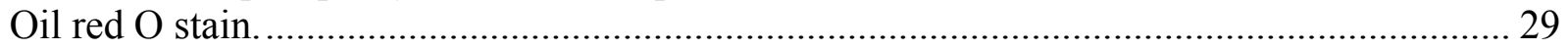

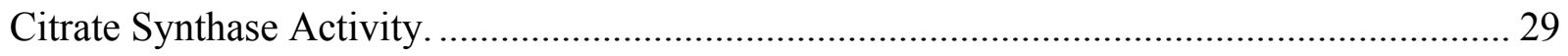

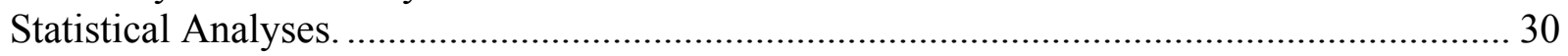

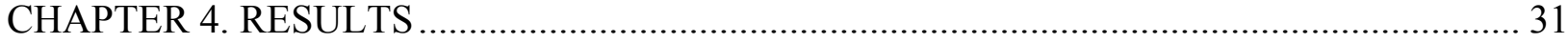

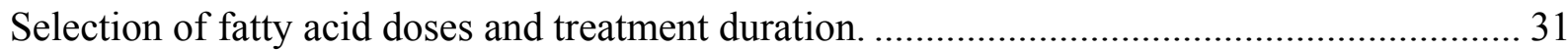

Palmitate-induced detriments to myotube morphology and size are attenuated by DHA......... 31

Palmitate treatment increases intramyocellular lipid content of myotubes. .............................. 32

DHA maintains protein abundance of oxidative markers in palmitate-treated myotubes........ 32

DHA attenuates palmitate-induced detriments in the insulin signaling pathway..................... 33

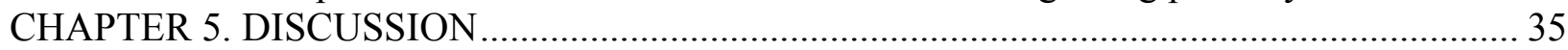

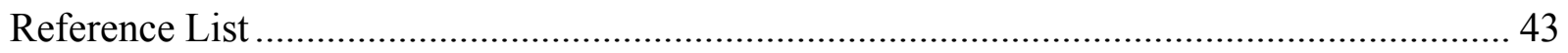




\section{TABLE OF FIGURES}

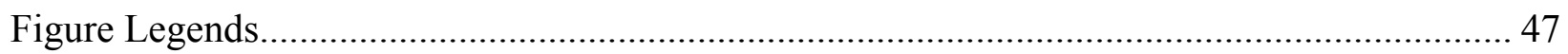

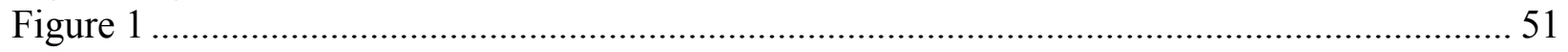

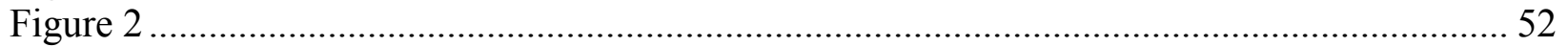

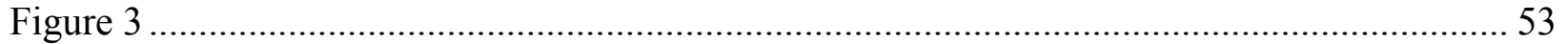

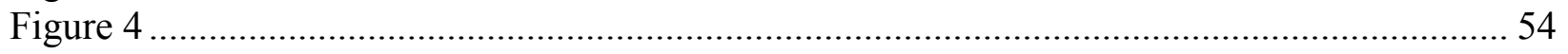

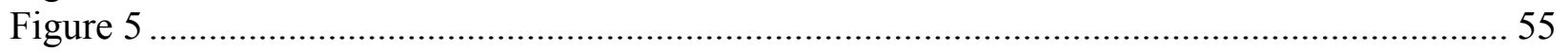

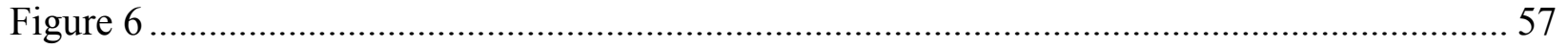

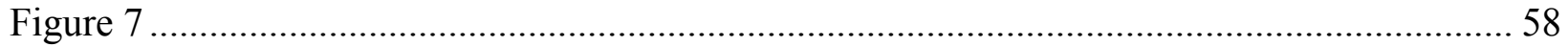

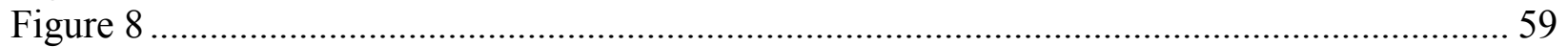

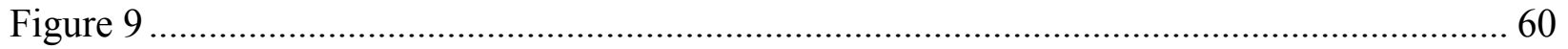




\section{CHAPTER 1. INTRODUCTION}

\subsection{Background and Significance}

Emergence of the lifestyle characterized by excessive nutrient intake and low physical activity levels has significantly contributed to the worldwide prevalence of overweight and obesity (67). The percentage of obese adults and children in the U.S. has increased to over onethird and almost one-fifth of the population, respectively, over the past 40 years $(55,67)$. Obesity is an established cause of insulin resistance (21), an early hallmark in the pathogenesis of type 2 diabetes (37) and cardiovascular disease (46). Insulin is the primary anabolic hormone that stimulates uptake and storage of nutrients in muscle, liver, and adipose tissue (47), and insulin resistance is defined as disturbances in insulin signaling that result in inappropriate responses of insulin-stimulated peripheral tissues to the actions of insulin (47) of normal or high concentrations (43).

The condition of obesity provides constant increased lipid flux into tissues (22), and lipid accumulation in non-adipose tissue can lead to cell dysfunction and/or death (87), termed lipotoxicity $(41,42,44,51,87)$. Implementation of a high fat (HF) diet is associated with abnormally high skeletal muscle lipid accumulation (87), which is highly correlated to skeletal muscle insulin resistance $(65,76)$ and is a more robust measurement of insulin resistance than body fat percentage, body mass index, and waist-to-hip ratio (22). However, both endurancetrained athletes (67) and previously untrained individuals who have undergone an endurancetraining program (60) also display increased fasting intramyocellular lipid content similar to or greater than levels found in individuals with type 2 diabetes but conversely possess enhanced insulin sensitivity $(42,59,65)$, a condition often termed the athlete's paradox (42). A low ability to oxidize accumulated fatty acids (FA) is an important contributor to formation of insulin resistance (44), and skeletal muscle oxidative capacity may be more important in determining insulin sensitivity than intramyocellular lipid content (67). Indeed, the athlete's paradox (42) distinguishes that accumulation of lipids in skeletal muscle is not harmful when adaptations in oxidative capacity are maintained and identifies the importance of targeting metabolic treatments toward enhancement of oxidative capacity.

Formation of insulin resistance is also partially related to the type of FA accumulated in the cell $(1,39,81)$. A chronic flux of saturated FA (SFA) are shown to have detrimental effects on 
cells (94) and lead to insulin resistance $(39,52)$, while exposure to unsaturated FA (UFA) prevents $(1,39,52,76,77)$, attenuates $(54)$, or reverses $(19,46,64)$ insulin resistance and when co-administered with SFA may prevent against detrimental metabolic effects associated with SFA treatment alone (52). Of particular interest are the long chain omega-3 (n-3) polyunsaturated FA (PUFA), such as docosahexaenoic acid (DHA). Supplementation of a small amount of long chain n-3 PUFA for other FA attenuates reductions in insulin sensitivity caused by oversupply of lipids $(1,77,81)$ and sucrose $(19,46,64)$ in cells $(1)$ and metabolically normal $(11,20,76,77)$, obese (54) and insulin resistant animals $(19,46,64)$. Omega PUFAs have the unique ability to partition FA toward oxidation (6), which identifies a possible role for the marine n-3 PUFA to improve insulin sensitivity by promoting skeletal muscle FA oxidation and reducing intramyocellular lipid content.

An enzyme that may participate in this mechanism is the AMP-activated protein kinase (AMPK), which controls systemic energy expenditure, glucose homeostasis, lipid metabolism (47), and mitochondrial biogenesis (62). AMPK is activated by phosphorylation of the threonine-172 (Thr172) residue of its $\alpha$-subunit (90) by an upstream kinase (84). The level of phosphorylated (p-) AMPK parallels the activity of AMPK (49), thus p-AMPK ${ }^{\text {Thr172 }}$ is an indicator of AMPK activity.

When activated, AMPK promotes insulin-independent glucose uptake in skeletal muscle (37, 74) and also centrally regulates fat metabolism both acutely and through long-term transcriptional control (75). Activated AMPK phosphorylates acetyl-CoA carboxylase $\beta$ at its serine-79 residue and inactivates it $(13,40,44,73,87,92,94,97)$, which removes inhibition of carnitine palmitoyl transferase-1 and promotes fat oxidation $(40,44,73,87,92,94,97)$.

Activated AMPK also phosphorylates and activates the PGC1 $\alpha$ protein on its threonine-177 and serine-538 residues in skeletal muscle, which activates PGC1 $\alpha$ gene expression in a feed-forward manner (32). Since PGC1 $\alpha$ is a master gene that regulates mitochondrial biogenesis (89), the expression and activity levels of the mitochondrial enzymes citrate synthase and cytochrome $c$ oxidase provide a method for assessment of oxidative changes downstream of AMPK activity $(57,69,70)$.

Treatments that activate AMPK are shown to improve insulin sensitivity $(17,29,30,44,56$, $72,91)$, and the ability of AMPK to enhance fatty acid oxidation and improve oxidative capacity identifies its possible value in controlling insulin resistance (4) through reductions in 
intramyocellular lipid content. Proper insulin signaling depends on the phosphorylation of specific tyrosine residues of the insulin-receptor substrate proteins (IRS) 1-4 (98), and the tyrosine phosphorylation of IRS-1 can be blocked by phosphorylation of particular IRS-1 serine (Ser) residues, including Ser636 (53), which effectively terminates insulin signal transduction (98). The serine cascade is activated by accumulation of intramyocellular lipid metabolites (53), and, as such, the phosphorylation of IRS-1 on Ser636 provides a method for evaluating the effects of FA on insulin signal transduction as a marker of skeletal muscle insulin resistance.

Long-term FA treatments have been demonstrated to inhibit AMPK $(44,49)$ and reduce insulin sensitivity (44) in rodent skeletal muscle, while n-3 PUFAs are shown to attenuate reductions in insulin sensitivity associated with nutrient oversupply $(10,46,68,81)$. However, there has been no published research to date examining the effects of marine n-3 PUFAs on AMPK phosphorylation in skeletal muscle cell culture, and there is limited literature (13) examining the skeletal muscle effects in vivo. Elucidating these effects may identify roles of marine n-3 PUFAs in improving skeletal muscle lipid homeostasis and contributing to insulin sensitivity through dis-inhibition of the insulin signaling pathway.

\subsection{Purpose and Specific Aims}

AMPK has the ability to regulate cellular lipid status (75) and mechanisms involved in oxidative metabolism $(32,40)$, and n-3 PUFAs promote FA oxidation over storage (6); therefore, the purpose of this thesis is to determine if n-3 PUFAs enhance FA oxidation and reduce intramyocellular lipid accumulation through activation of the AMPK signaling pathway. The central hypothesis is that long-term DHA treatment of $\mathrm{C}_{2} \mathrm{C}_{12}$ myotubes will activate the AMPK pathway to improve oxidative metabolism, reduce intramyocellular lipid content and enhance insulin signaling.

Specific Aim 1. Determine the long-term effects of palmitate and DHA on AMPK and ACC phosphorylation in cultured myotubes.

Hypothesis 1.1. Long-term palmitate treatment will lead to a reduction in the phosphorylation of $\mathrm{AMPK}^{\mathrm{Thr172}}$ and $\mathrm{ACC}^{\mathrm{Ser} 79}$ in myotubes.

Hypothesis 1.2. Long-term DHA treatment will increase the phosphorylation of $\mathrm{AMPK}^{\mathrm{Thr} 172}$ and $\mathrm{ACC}^{\mathrm{Ser} 79}$ in myotubes. 
Hypothesis 1.3. Long-term DHA treatment will attenuate the palmitate-induced decrease in the phosphorylation of $\mathrm{AMPK}^{\text {Thr172 }}$ and $\mathrm{ACC}^{\text {Ser79 }}$ in myotubes.

Specific Aim 2. Determine the long-term effects of palmitate and DHA on the oxidative capacity of cultured myotubes by evaluating the enzyme activity of citrate synthase (CS) and the protein expression levels of PGC1 $\alpha$ and cytochrome c oxidase (COX) IV.

Hypothesis 2.1. Long-term palmitate treatment will decrease CS activity and reduce protein expression of PGC1 $\alpha$ and COXIV in myotubes.

Hypothesis 2.2. Long-term DHA treatment will increase the activity of CS enhance protein expression of PGC1 $\alpha$ and COXIV versus control myotubes.

Hypothesis 2.3. Long-term DHA treatment will attenuate the palmitate-induced decreases in the activity of CS and the protein expression of PGC1 $\alpha$ and COXIV in myotubes.

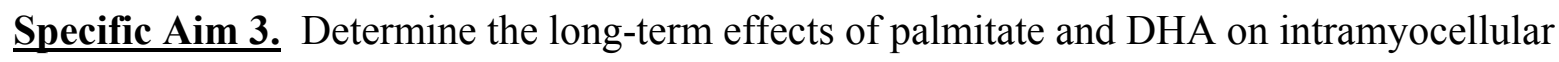
lipid content of cultured myotubes and any related changes in insulin signaling as determined by phosphorylation of the insulin receptor substrate 1 (IRS-1) on serine 636/639.

Hypothesis 3.1. Long-term palmitate treatment will increase the intramyocellular lipid content of myotubes and the phosphorylation of IRS-1 $1^{\text {Ser636/639. }}$.

Hypothesis 3.2. Long-term DHA treatment will not change intramyocellular lipid content of myotubes from control levels or lead to increases in phosphorylation of IRS-1 ${ }^{\text {Ser636/639. }}$.

Hypothesis 3.3. Long-term DHA treatment will attenuate the palmitate-induced increases in intramyocellular lipid content and phosphorylation of IRS-1 $1^{\text {Ser636/639. }}$ 


\section{CHAPTER 2. REVIEW OF LITERATURE}

\subsection{Obesity contributes to the formation of insulin resistance and other chronic diseases}

Excessive nutrient intake and low physical activity levels significantly contribute to the development of overweight and obesity. Overweight is defined as a body mass index (BMI) of

$25 \mathrm{~kg} / \mathrm{m}^{2}-29.9 \mathrm{~kg} / \mathrm{m}^{2}$, and obesity is defined as BMI $\geq 30 \mathrm{~kg} / \mathrm{m}^{2}$ (67). In the year 2000 , the percentage of overweight and obese individuals over 20 years old in the United States was $63 \%$ and $30 \%$, respectively (67). Furthermore, the prevalence of individuals with extreme obesity $\left(\mathrm{BMI} \geq 40 \mathrm{~kg} / \mathrm{m}^{2}\right)$ has increased by $2.8 \%$ in men and $6.9 \%$ in women as of $2004(55)$. The prevalence of obesity in children ages 6-19 years has increased from 4\% to $17.1 \%$ between 1960 $2004(55,67)$, which is alarming because overweight children are more likely to be overweight or obese as adults (25). Obesity and weight gain are established causes of insulin resistance and type 2 diabetes (21), and complications accompanying type 2 diabetes are a major cause of disability and death (72). Obesity and weight gain also increase the risk for many other disorders, such as high blood pressure, high cholesterol, asthma, arthritis, and cardiovascular disease (67). The developing obesity epidemic in adults, adolescents, and children across the globe will continue to have enormous implications on healthcare and supporting research for many years to come. To reduce the future incidence of these diseases, multiple treatment strategies are needed that normalize metabolic control and prevent mortality-associated systemic complications (72).

\subsection{Obesity is associated with intramyocellular triglyceride accumulation and formation of bioactive lipid species that contribute to insulin resistance}

Skeletal muscle from obese humans displays an increased quantity of fatty acid (FA) transporters in the muscle membrane (71) and increased rates of fatty acid uptake $(71,74)$ and esterification (74), as well as decreased contents of cytosolic FA binding protein for intracellular FA transport $(50)$ and reduced rates of FA oxidation $(71,74)$. Together these factors lead to the obesity-associated phenotypic characteristic of accelerated intramyocellular triglyceride synthesis (22). Skeletal muscle from high-fat fed animals is also shown to have a higher rate of intramyocellular triglyceride turnover than that of lean littermates, which leads to chronically increased levels of lipid intermediates (22). 
When a long chain FA enters the cell, it is rapidly converted to fatty acyl CoA (FACoA) by acyl CoA synthetase (22). This conversion is a required step for entrance into several different metabolic processes, which is dictated by the structure of the FA (34). FACoA can undergo elongation and/or desaturation or be formed into complex lipids such as membrane phospholipids (34). FACoA can also be converted to long chain acylcarnitine by carnitine palmitoyl transferase-1 (CPT-1) and immediately $\beta$-oxidized by the mitochondria, or it can be converted to the lipid intermediate diacylglycerol and then to triacylglycerol (TAG or TG) for storage (67). When a stored TG molecule is hydrolyzed, one molecule each of diacylglycerol and FACoA is released (22), and, as such, a chronic FA flux can lead to intracellular accumulation of diacylglycerol and FACoA $(73,92)$ either directly through esterification or indirectly through TG accumulation and subsequent hydrolysis.

Diacylglycerol, long chain FaCoA (22) and ceramides (75) are bioactive lipid signaling molecules that can enter and interfere with non-oxidative metabolic pathways (88), leading to lipotoxic defects such as formation of insulin resistance (22). One mechanism underlying lipotoxic insulin resistance is through defects in the insulin signaling pathway. Binding of insulin to its transmembrane receptor stimulates the phosphorylation of specific tyrosine residues of numerous target proteins, including the insulin-receptor substrate proteins (IRS) 1-4, which then associate with other downstream kinases to ultimately mediate the metabolic and growthpromoting functions of insulin (98). However, the tyrosine phosphorylation of IRS-1 can be blocked by phosphorylation of particular IRS-1 serine (Ser) residues, including Ser636 (53) and Ser1101, the latter of which has been associated with IRS-1 degredation (33). Serine phosphorylation of IRS-1 uncouples the protein from its upstream and downstream effectors and terminates signal transduction from insulin (98). It has been demonstrated that the serine cascade is activated by accumulation of intramyocellular lipid metabolites (53). Therefore, the phosphorylation of IRS-1 on Ser636 and Ser1101 provides a method for evaluating the effects of FA on insulin signal transduction as a marker of skeletal muscle insulin resistance. 


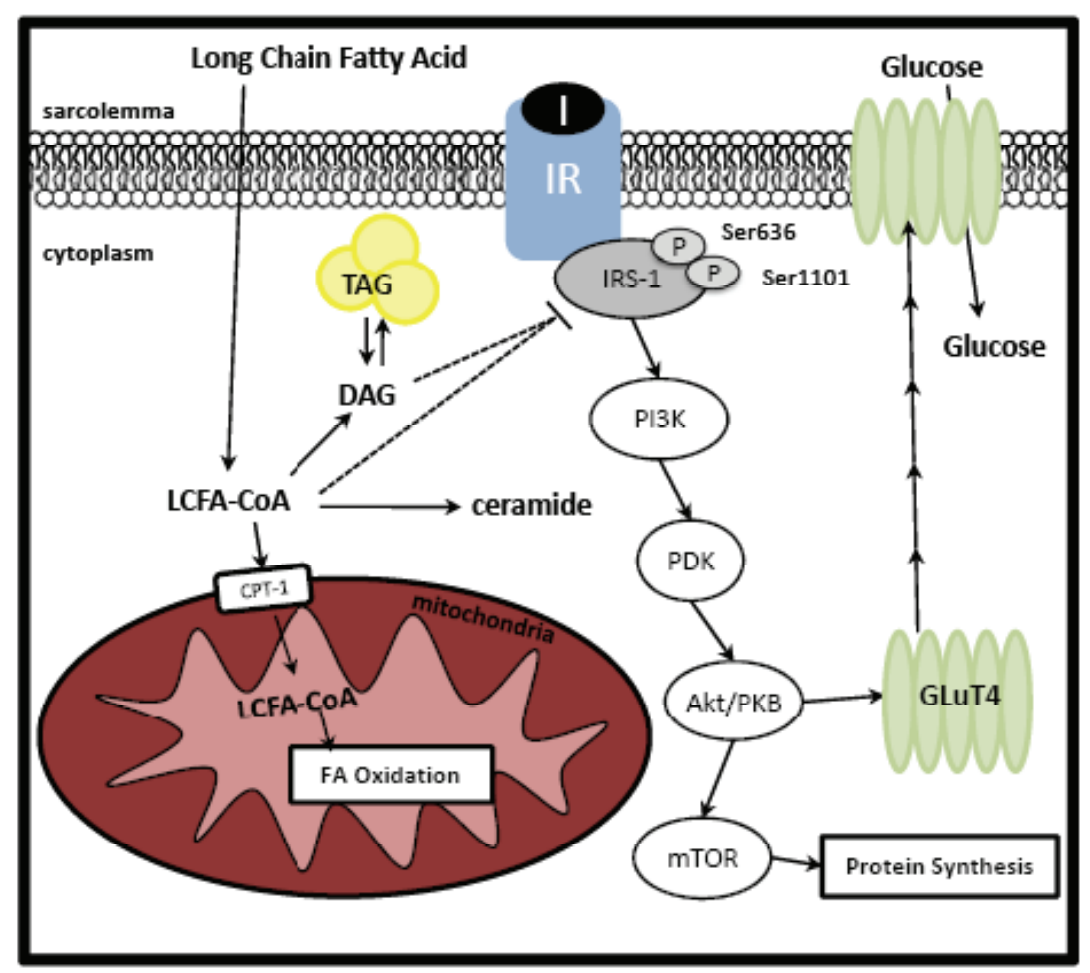

\subsection{AMPK is a master metabolic regulator}

\subsubsection{AMPK is important in systemic metabolism}

The adenosine monophosphate-activated protein kinase (AMPK) pathway is a possible target for treatment of insulin resistance (4). AMPK is a conserved cellular energy gauge $(51,90,94)$ that serves as a master metabolic regulator by controlling systemic energy expenditure, food intake, glucose homeostasis, and lipid metabolism (47). The protein kinase is activated in conditions of energy depletion $(17,40)$ or metabolic stress $(28)$, such as muscle contraction $(17$, $37)$, exercise $(17,56)$, and hypoxia (37), and can also be stimulated pharmacologically (44, 56, 91). Activation of AMPK acts to conserve cellular energy stores $(47,73)$ by acutely suppressing energy-consuming pathways, such as synthesis of glycogen, cholesterol, and lipids (73), and inducing energy-producing pathways, such as glucose uptake (94) and FA oxidation $(92,94)$. AMPK is an important regulator of insulin-independent glucose uptake into tissues by promoting glucose transporter 4 (GluT4) translocation to the sarcolemma (37), as well as increased expression (47), phosphorylation, and activation (74) of transcription factors regulating the GluT4 gene promoter. Also of particular interest is the ability of AMPK to sense the lipid status of a cell $(90,94)$, independent of cellular energy charge (92). 


\subsubsection{Enzymatic characteristics of $A M P K$}

AMPK is a heterotrimeric enzyme formed by $\alpha, \beta$, and $\gamma$ subunits $(47,84,94)$. Each subunit has multiple isoforms encoded by separate genes: $\alpha 1, \alpha 2, \beta 1, \beta 2, \gamma 1, \gamma 2$, and $\gamma 3$ (75). AMPK is ubiquitously expressed in mammalian tissues, though some tissue-specific expression is observed with the $\beta$ and $\gamma$ subunits and the contribution of each $\alpha$ isoform to total AMPK activity (4). Skeletal muscle AMPK complexes mostly contain $\alpha 2 / \beta 2,80 \%$ of which are associated with $\gamma 1$ (73), though glycolytic skeletal muscle predominately contains $\alpha 2 / \beta 2 / \gamma 3$ complexes (4).

The $\alpha$ subunit provides the catalytic activity of $\operatorname{AMPK}(75,94)$ and contributes to AMP binding (4). In skeletal muscle, the $\alpha 1$ subunit is predominately cytoplasmic (84), while the $\alpha 2$ subunit is located in the cytoplasm and nucleus, and cytoplasmic $\alpha 2$ translocates to the nucleus upon stimulation (80), indicating its participation in regulation of gene expression. The regulatory $\beta$ subunit serves as a docking area for $\alpha$ and $\gamma$ subunits and also contains a glycogen binding domain (75), suggesting a possible role in glycogen feedback regulation of AMPK (4). Additionally, the $\beta$ subunit is important for determining the localization of the $\alpha$ subunit; in $\mathrm{C}_{2} \mathrm{C}_{12}$ skeletal muscle cells, $\beta 2$ is shown to aide in the nuclear localization of $\alpha 2$, while $\beta 1$ contributes to the return of $\alpha 2$ to the cytoplasm after stimulation (80). The $\gamma$ subunit is responsible for binding AMP or ATP and thus provides for allosteric control of AMPK (75). It also stabilizes the $\alpha$ subunit and is essential for the catalytic activity of AMPK (4). The $\gamma 1$ and $\gamma 2$-isoforms are widely distributed throughout tissues, while the $\gamma 3$-isoform is highly specific for glycolytic skeletal muscle where it plays a role in regulation of carbohydrate metabolism (4) but not lipid oxidation (3). The $\gamma 1$ isoform is the only $\gamma$ subunit expressed in C2C12 cells and is required for both phosphorylation and nuclear translocation of $\alpha 2(80)$.

\subsubsection{Allosteric modulation and phosphorylation of AMPK}

Multiple mechanisms contribute to regulation of the AMPK pathway, which varies between tissues (47). AMPK can be regulated through both allosteric modulation and phosphorylation. Allosteric activation of AMPK due to increasing concentrations of cellular AMP (94) leads to a 5-fold increase (84) in the enzymatic activity of AMPK. AMPK can also be allosterically inhibited by the presence of physiological concentrations of phosphocreatine $(13,24)$ and adenosine triphosphate (ATP) (73). Importantly, allosteric binding of AMP also both facilitates the phosphorylation of AMPK on the threonine-172 (Thr172) residue in the activation loop of 
the $\alpha$-subunit (90) by an upstream kinase and reduces the inhibitory dephosphorylation of AMPK $^{\text {Thr172 }}$ by its upstream phosphatases (84). Phosphorylation of AMPK results in a 100-fold increase in AMPK activity $(23,84)$, and when combined with allosteric modulation produces greater than 1000-fold activation of AMPK (23). Since the level of phosphorylated (p-) AMPK parallels the activity of AMPK (49), p-AMPK $^{\text {Thr172 }}$ is commonly used to indicate AMPK activity. Furthermore, phosphorylation of AMPK on its Ser485/491 residues has been associated with a decrease in phosphorylation of $\operatorname{AMPK}^{\mathrm{Thr172}}(27)$, indicating its usefulness as a measure of AMPK inactivation.

The primary upstream kinase activating AMPK is the tumour suppressor kinase (LKB1) (73, $75,84)$, which phosphorylates AMPK $\alpha^{\text {Thr172 }}$ in response to increasing AMP concentrations (84). The calcium/calmodulin-dependent protein kinase kinase (CaMKK) shows significant homology to LKB1 and has also been identified as an AMPK-activator (28). CaMKK is activated by increasing intracellular calcium levels and regulates AMPK independently of the AMP/ATP ratio (47). The primary upstream phosphatases to AMPK are the protein phosphatases (PP) $2 \mathrm{C}$ (73) and 2A (74). Adipose tissue also exerts effects on skeletal muscle fuel metabolism, as the adipokines adiponectin and leptin have been identified as AMPK-activators $(51,96)$. Leptin is adipocyte-derived protein hormone secreted in proportion to fat storage content (49) that helps regulate energy flow (35). Leptin has been shown to decrease peripheral TG storage and improve insulin sensitivity (47) through improvement of FA oxidation in skeletal muscle cells $(51,80)$. Adiponectin is a protein also secreted exclusively by adipocytes (64). Decreased expression of adiponectin correlates with insulin resistance, and treatments that stimulate production of adiponectin are associated with enhanced insulin sensitivity (64). Both leptin and adiponectin stimulate FA oxidation in skeletal muscle through phosphorylation of AMPK $\alpha$ (96), which depends on translocation of the $\alpha 2$ subunit from the cytoplasm to the nucleus (80).

\subsubsection{AMPK contributes to acute and chronic lipid homeostasis}

AMPK is a central regulator of fat metabolism both acutely and through long-term transcriptional control (75). Classically, AMPK promotes FA oxidation by phosphorylating and inactivating acetyl-CoA carboxylase $\beta(\mathrm{ACC} \beta)$, the rate-limiting enzyme of malonyl-CoA synthesis $(40,44,73,87,92,94,97)$. The phosphorylation of ACC $\beta$ at its serine-79 (Ser79)

residue is accomplished almost exclusively by AMPK (13), thus p-ACC ${ }^{\text {Ser79 }}$ is an excellent 
downstream marker for secondary measurement of AMPK activity. AMPK also phosphorylates and activates malonyl-CoA decarboxylase (MCD), which degrades malonyl-CoA. Malonyl acts as a powerful allosteric inhibitor of CPT-1, which shuttles FACoAs into the mitochondria for $\beta$ oxidation. The effects of AMPK on ACC and MCD cause a reduction in the level of malonylCoA, subsequently disinhibiting CPT-1 and promoting fat translocation and oxidation (40, 44, $73,87,92,94,97)$.

AMPK also regulates long-term lipid metabolism and mitochondrial biogenesis by increasing expression of genes involved in FA metabolism (40) and mitochondrial proteins involved in oxidation (62). AMPK is shown to increase FA oxidation in myotubes in a dose-dependent manner (40), which occurs with an increase in mRNA expression of the peroxisome-proliferatoractivated receptor (PPAR) $\gamma$ co-activator $1 \alpha(\mathrm{PGC} 1 \alpha)(40)$ but not PGC1 $\beta$ (32). PGC1 $\alpha$ is a master gene that regulates mitochondrial biogenesis (89) and co-activates the PPAR $\alpha$ to regulate transcriptional control of FA oxidation (40). AMPK directly phosphorylates and activates the PGCl $\alpha$ protein on its threonine-177 and serine-538 residues in skeletal muscle, which activates PGCl $\alpha$ gene expression in a feed-forward manner (32). AMPK activation promotes expression of the mitochondrial gene cytochrome $c$ and increases total mitochondrial respiration, which is dependent upon the presence of PGC1 $\alpha$ (32). This indicates that activation of AMPK can enhance oxidative capacity by improving mitochondrial biogenesis via PGC1 $\alpha$. AMPK also increases mRNA expression of PPAR $\alpha$ and its target genes CPT- 1 and fatty acid binding protein 3 (FABP3) in myotubes and rodent skeletal muscle (40), which indicates its ability to facilitate FA oxidation. 


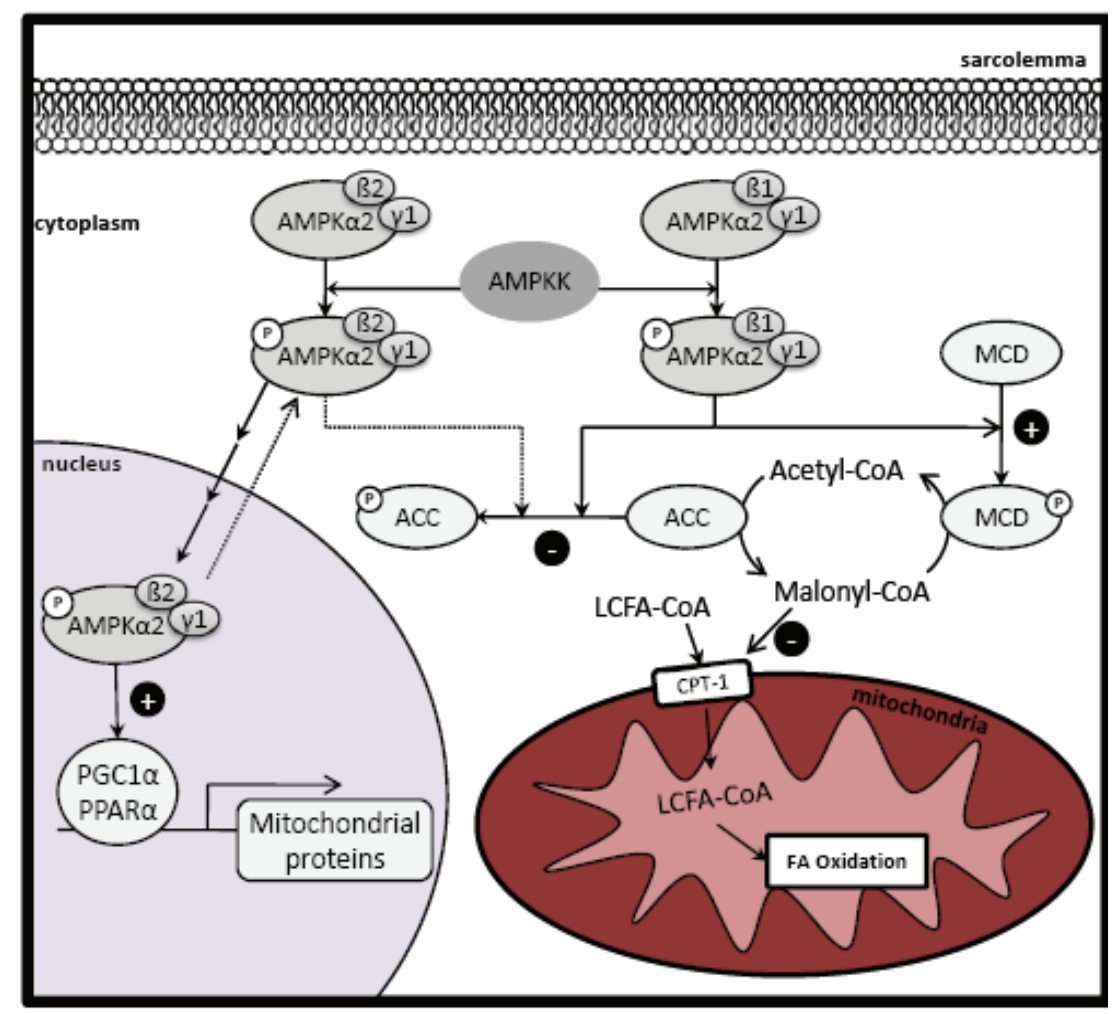

\subsubsection{Oxidative capacity is decreased with insulin resistance}

Reductions in mitochondrial density and activity contribute to reduced oxidative capacity and dysregulated lipid metabolism (62) and aide in the development of skeletal muscle insulin resistance (47). A common method for assessment of oxidative capacity is measurement of expression and activity levels of the mitochondrial enzymes citrate synthase (CS) and cytochrome c oxidase (COX), which are shown to increase in response to aerobic exercise training in metabolically normal animals $(69,70)$ and in insulin resistant humans $(57)$ and are decreased in conditions of insulin resistance. Insulin resistant offspring of individuals with type 2 diabetes have been shown to exhibit a trend toward lower baseline COX and CS activity levels (57), as well as possess 38\% lower mitochondrial density and 50\% lower expression of COX versus insulin-sensitive individuals, which is associated with $60 \%$ greater intramyocellular lipid content (53). Maximal COX activity was also reduced by almost $50 \%$ after 6 weeks of high-fat and high-sucrose feeding of male Wistar rats versus control animals (5). 


\subsubsection{Activation of AMPK enhances oxidative capacity}

The ability of AMPK to reduce skeletal muscle TG content by stimulating FA oxidation (44, 47) and enhancing lipid oxidative capacity (4) is important in its distinction as a positive regulator of insulin sensitivity $(44,47)$. The compounds 5 -aminoimidazole-4-carboxamide ribonucleoside (AICAR) (91) and metformin (44) are pharmacological stimulators of AMPK. AICAR potently activates AMPK (91) in cells upon formation of the adenosine analogue ZMP $(40,47)$, while AMPK is an indirect target of metformin (32). While it is possible that AICAR may also affect other AMP-sensitive enzymes, it is commonly used to examine the effects of AMPK activation on cellular processes $(9,17,29,30,37,56,61,62)$. AICAR is shown to increase skeletal muscle FA oxidation $(32,40)$ and PPAR $\alpha(40), \operatorname{PGC} 1 \alpha(32,40), \mathrm{CPT}-1$, and FABP3 mRNA expression (40), and both AICAR and metformin increase the mRNA expression of cytochrome $c$ and uncoupling proteins-2 and -3 (32) in skeletal muscle cells.

Treatment of male Sprague-Dawley rats with AICAR for 4 weeks significantly increased cytochrome $c$ protein content in white quadriceps as well as the activity of CS, succinate dehydrogenase, and malate dehydrogenase in white quadriceps and soleus muscles (93). Furthermore, administration of oral metformin for 14 days to male Wistar rats increased PGC1 $\alpha$ protein content and CS activity in soleus and red and white gastrocnemius muscles, as well as cytochrome $c$ protein content in the soleus (79). These studies examining the effects of AICAR and metformin on AMPK activity and subsequent FA oxidation and mitochondrial oxidative capacity identify the possible value of AMPK-activating treatments in controlling insulin resistance (4) through changes in lipid homeostasis.

\subsection{Fatty acid treatments alter skeletal muscle AMPK}

FA treatments have been shown to both activate $(78,92,94)$ and repress $(44,83)$ AMPK phosphorylation and activity, but the outcome is dependent upon the type of FA and the length of treatment. The saturated fatty acid (SFA) palmitate comprises between $30-40 \%$ of FA in the plasma (94) and is commonly used $(7,8,14-16,18,29,31,39,41,52,56,59,63,65,83,85,90$, $92,94)$ along with the monounsaturated fatty acid (MUFA) oleate $(1,7,8,18,39,41,52,59,65$, $92,94)$ and omega- $6(n-6)$ polyunsaturated fatty acid (PUFA) linoleate $(39,92)$ to study the effects of different FAs on metabolic markers. Acute palmitate $(10,76)$ and linoleate $(76)$ treatments have been shown to promote skeletal muscle AMPK and ACC phosphorylation (15, 
92), while chronic treatment with palmitate (94) and palmitoyl-CoA (83), as well as long-term high-fat (HF) feeding with primarily SFA $(44,49)$, have been shown to repress AMPK in skeletal muscle and other cell types.

\subsubsection{Acute fatty acid treatments stimulate AMPK activity}

Treatment of L6 myotubes for 1 hour with $0.25 \mathrm{mM}$ of SFA palmitate or PUFA linoleate significantly increased AMPK activity, phosphorylated (p-) AMPK ${ }^{\text {Thr172 }}$, and p-ACC $\beta^{\text {Ser218 }}$ with no changes in cellular energy charge. Both palmitate and linoleate pre-treatments increased subsequent palmitate oxidation rates (92). In a similar study, L6 myotubes incubated for 1 hour with 0.001-0.8 mM palmitate demonstrated a dose-response increase in $\mathrm{p}-\mathrm{AMPK} \alpha^{\mathrm{Thr} 172}$ and $\mathrm{p}$ $\mathrm{ACC}^{\mathrm{Ser} 79}$ levels, which was significant with as little as $0.01 \mathrm{mM}$ palmitate and peaked with 0.4 $\mathrm{mM}$ palmitate at 3.5-fold for AMPK and 4.5-fold for ACC. Furthermore, as palmitate concentration increased so did its oxidation (15). Similar effects are also observed in a different cell type, as acute treatment of bovine arterial endothelial cells (BAECs) with palmitate resulted in increased p-AMPK and p-ACC versus control-treated cells (94). Together these data indicate that acute treatment with FA leads to activation of AMPK and inactivation of ACC to promote FA oxidation, which supports an acute feed-forward mechanism where increased lipid availability enhances FA oxidation to allow non-adipose cells to adapt to increasing FA flux without initially changing lipid storage capacity.

\subsubsection{Long-term fatty acid treatments repress basal AMPK activity but may not affect the ability of AMPK to be chronically activated}

More applicable to the condition of obesity is long-term FA treatment that increases cellular and tissue lipid concentrations and detrimentally affects metabolic pathways. For example, although palmitate treatment led to an initial activation of p-AMPK and p-ACC levels in BAECs, these values returned to basal levels by 5 hours, and both basal and AICAR-stimulated p-AMPK and p-ACC were significantly decreased with long-term treatment for 40 hours, which was not due to increased ATP from palmitate oxidation or reduced AMPK or ACC expression (94). This clearly identifies the opposing effects of FA on AMPK and ACC phosphorylation in acute versus chronic conditions and distinguishes that the same effects may occur in skeletal muscle. 
Indeed, animal HF feeding studies mimic the Western diet of nutrient oversupply and have been shown to inhibit AMPK in rodent skeletal muscle $(44,49)$. Male Wistar rats fed a 22\% fat diet of predominately lard for 5 months demonstrated significant decreases in basal total- and phosphorylated-AMPK $\alpha$ protein, AMPK $\alpha 2$ mRNA, and p-ACC protein versus chow-fed animals in the gastrocnemius muscle, which was associated with decreased basal and insulin-stimulated glucose uptake during hyperinsulinemic clamping. However, animals receiving oral metformin during the last month of feeding displayed an attenuation of insulin resistance as evidenced by significant increases in the glucose infusion rate (GIR) during clamping, which was associated with $162 \%$ and $39 \%$ increases in basal p-AMPKo $\alpha^{\text {Thr172 }}$ and p-ACC levels, respectively (44). This data suggests that although basal AMPK activity and expression is decreased in skeletal muscle of HF-fed animals, they maintain the capacity to improve these levels through chronic pharmacological activation, which is also associated with enhanced insulin sensitivity.

Young male FVB mice fed a 55\% fat diet of predominately lard for 5-12 weeks showed impaired AMPK phosphorylation and activity in response to leptin administration in the soleus muscle but demonstrated unimpaired AMPK activation by AICAR (49), identifying that these animals were leptin resistant but still maintained the ability to sense cellular energy charge. Furthermore, another group (36) reported that 3-week old male Wistar rats fed a 50\% fat diet for 4 weeks were insulin resistant but did not display significantly different hypoxia-stimulated pAMPK levels than chow-fed animals. These studies suggest that HF-feeding does not affect the ability of skeletal muscle AMPK to become activated by agents other than leptin, indicating that these pathways may be targeted to induce positive metabolic effects. However, feeding studies of over 14 weeks are considered long-term in rats (46); therefore, further studies are needed to identify the ability of skeletal muscle AMPK to be activated after chronic HF-feeding. Chronic SFA treatment of BAECs led to reduced basal and AICAR-activated AMPK levels (94), highlighting the need for these studies in skeletal muscle.

Together these data suggest that short-term HF feeding does not alter the ability of AMPK to be activated and leads to adaptations in FA oxidation to meet cellular needs, while long-term HFfeeding leads to decreased basal AMPK activity and overcomes the adaptive capacity of the muscle for FA oxidation when unaided by pharmacological activators or stress-inducing conditions. These studies did not examine the effects of PUFA supplementation on basal and 
stimulated p-AMPK levels, which may identify cellular role(s) of PUFAs in metabolic regulation of lipid metabolism through alteration of skeletal muscle AMPK activity.

\subsection{Cellular effects of fatty acids depend on their structures}

\subsubsection{Saturated and unsaturated fatty acids differentially affect cellular metabolism}

The effects of dietary FA on health depend not only on the quantity but also on the nature of the fatty acids (48). A chronic flux of SFA is demonstrated to have detrimental metabolic effects in cells $(52,65,94)$ and skeletal muscle $(39)$ and is associated with formation of insulin resistance $(39,52)$, while exposure to unsaturated fatty acids (UFA) prevents (1) $(11,39,52,76$, $77)$, attenuates (54), or reverses insulin resistance $(19,46,64)$. Interestingly, there is also evidence that UFA co-administered with SFA offers prevention against detrimental metabolic effects associated with SFA treatment alone, improving lipid homeostasis (7) and promoting insulin sensitivity (52).

Myotubes incubated with palmitate showed increased accumulation of diacylglycerol and formation of insulin resistance, while cells incubated with oleate had increased TG levels and no changes in insulin sensitivity. Co-incubation of palmitate + oleate also led to increased TG content and prevented insulin resistance in a dose-dependent manner. Furthermore, palmitate treatment led to a reduction in PGC1 $\alpha$ mRNA expression, while cells treated with oleate alone and palmitate + oleate had PGC1 $\alpha$ expression levels similar to control values and actually demonstrated an approximate 7-fold increase in CPT-1 mRNA expression (7). This data indicates that SFA treatment induces insulin resistance and downregulates the expression of the mitochondrial regulator PGC1 $\alpha$, while UFA treatment leads to maintenance of mitochondrial biogenesis and improvement in FA oxidation capacity and can actually prevent detrimental effects of SFA on these parameters.

\subsubsection{Omega-3 polyunsaturated fatty acids enhance insulin sensitivity}

In addition to the positive effects of the MUFA oleate on prevention of insulin resistance, a great deal of literature has examined the metabolic effects of PUFAs. The n-6 PUFA linoleic acid and the omega-3 (n-3) PUFA linolenic acid are considered essential fatty acids because they cannot be synthesized by mammals and must be consumed from dietary sources (66). Metabolism of linolenic acid gives rise to two other FA (12) of particular interest in regards to 
insulin resistance, the long chain n-3 PUFAs eicosapentaenoic acid (EPA; C20:5 n-3) and docosahexaenoic acid (DHA; C22:6 n-3). EPA and DHA are primarily found in fish, shellfish, and sea mammals and are sparse or absent in plants and land animals (45), and at least 30 marketed species of Mediterranean fish and shellfish provide significant sources of $n-3$ PUFAs by containing high levels of EPA and DHA (58). In the literature these PUFAs are often administered in the form of fish oil (FO) (20). Conversely, n-6 PUFAs are found in foods of animal origin and in vegetable oils (66). Currently more than $85 \%$ of the total dietary PUFA intake in Western diets is of the n-6 moiety, while consumption of n-3 PUFAs has declined (48). This may be one contributor to the rise in obesity-associated disease, as high intake of n- 6 PUFAs has been associated with childhood obesity (48) and may lead to hyperinsulinaemia and insulin resistance in adults (95).

In 1987, Storlein et al. (77) demonstrated that substituting a small amount of n-3 PUFAs in the form of FO for n-6 PUFAs in a HF diet attenuated reductions in insulin sensitivity observed with a HF-diet alone. Since this discovery, a plethora of research has been aimed at identifying the mechanisms underlying these beneficial effects. Although it has been demonstrated that n-3 PUFA improve components of the insulin-signaling pathway in skeletal muscle $(20,38,81)$, their effects outside of the insulin-signaling pathway remain unclear. PUFAs have the unique ability to partition FA toward oxidation (6), which identifies a possible role for the marine n-3 PUFAs to improve skeletal muscle insulin sensitivity by promoting FA oxidation and reducing of intramyocellular lipid content. Therefore, focus will be maintained on studies identifying effects of n-3 PUFAs on blood and skeletal muscle lipid parameters to assess possible changes in FA flux, lipid synthesis, and oxidative metabolism as they relate to alterations in insulin sensitivity. Little research is available on the effects of n-3 PUFAs on skeletal muscle oxidative capacity, though one study did report that male Wistar rats fed a HF diet containing 10\% n-3 PUFA $+18 \%$ SFA exhibited $48 \%$ and $83 \%$ increases in skeletal muscle acyl-CoA oxidase activity and mRNA expression, respectively, versus rats fed a HF diet containing $28 \%$ SFA. This was associated with a normalization of the GIR during hyperinsulinemic clamping, indicating an enhancement of systemic insulin sensitivity (86).

Aside from direct measurements of FA oxidation and mitochondrial proteins and enzymatic activities, changes in intramyocellular lipid contents are indicators of the possible effects of n-3 PUFAs on fatty acid metabolism in skeletal muscle. Male Wistar rats were fed a control diet 
(CON), a $70 \%$ fat diet (HF), or a HF diet with either 10\% replacement of SFA with n-3 PUFAs from $\mathrm{FO}(\mathrm{HF}+\mathrm{FO})$ or $18.5 \%$ replacement of SFA with the n-6 PUFA gamma-linolenic acid from borage oil (HF+GLA) for 3 weeks. The HF diet led to increased fasting insulin levels and postprandial free FA, TG, and glycerol levels, which were normalized by FO but not GLA supplementation. Interestingly, the plasma TG levels in the $\mathrm{HF}+\mathrm{FO}$ group were even significantly lower than the control group by about 50\%. The GIR during hyperinsulinemic clamping was about $60 \%$ lower in HF versus control animals and was significantly increased with FO supplementation. Skeletal muscle TG contents were similar in control and HF+FO groups and were significantly lower than in animals fed HF or HF+GLA diets (68). These data clearly indicate the hypolipidemic effect of n-3 PUFAs in blood and skeletal muscle and its association with improved systemic insulin sensitivity.

Other studies have also assessed the effectiveness of n-3 PUFA supplementation in prevention of insulin resistance. Male Wistar rats were fed diets containing 18.5\% fat, composed of either $8 \%$ corn oil (control diet, $\mathrm{CD}$ ) or $1 \%$ corn oil $+7 \%$ cod liver oil (CD+CLO) for 1 month. CLO is high in the n-3 PUFAs EPA and DHA (82). The CD+CLO group exhibited significantly lower plasma TG and insulin levels and significantly higher GIR during euglycemic-hyperinsulinemic clamping compared to CD-fed animals (11), demonstrating an association between short-term CLO supplementation and prevention of insulin resistance in metabolically normal rats through improvements in systemic glucose utilization and reductions in plasma TG levels.

Since CLO supplementation prevented fat-induced insulin resistance in normal animals, the same group (46) evaluated the possibility that CLO supplementation could reverse diet-induced insulin resistance. Young male Wistar rats were fed a sucrose-rich diet (SRD, 8\% corn oil) for 6 months to induce dyslipidemia and insulin resistance, after which the animals were split into 2 groups and fed for 2 more months with either the same SRD or one where the $8 \%$ corn oil was replaced by $1 \%$ corn oil $+7 \%$ CLO (SRD+CLO). CLO supplementation restored gastrocnemius TG content to control levels and significantly reduced diacylglycerol and FACoA content versus SRD-feeding (46), suggesting either improvement in FA oxidation or reduction in TG synthesis. Additionally, the SRD was associated with increased fasting plasma TG, FFA, and glucose concentrations and led to over 50\% reduction in GIR during clamping versus the CD, while CLO supplementation elicited values similar to CD-fed animals (46). These studies indicate that CLO 
supplementation is associated with normalization of skeletal muscle lipid content and improved glucose homeostasis during fasting and insulin-stimulated conditions.

Mustad et al. (54) expanded the literature by examining the possibility of different n-3 PUFA supplements ( $\alpha$-linolenic acid [ALA], EPA, or DHA) to improve glucose metabolism and insulin sensitivity in HF-fed $o b / o b$ mice. Mice were fed MUFA-rich diets [43-45\% fat, 37-39\% CHO, and $18 \%$ protein] with n-3 PUFA percentages of either 1.2\% (MUFA), $24.6 \%$ (ALA), 36.6\% (EPA), or 34.7\% (DHA) for 4 weeks. EPA and DHA groups had lower plasma TG and free FA levels than the MUFA group, which is similar to other findings $(19,46)$. The plasma glucose concentration 2 hours post-meal was also significantly reduced by $40-50 \%$ in all n-3 PUFA groups compared to MUFA-fed mice, indicating improved glucose utilization in response to feeding (54) which may have occurred through activation of the AMPK pathway.

\subsection{Polyunsaturated fatty acids may alter skeletal muscle AMPK to improve insulin sensitivity}

It is clearly established that treatment with n-3 PUFAs exerts positive effects on insulin sensitivity in skeletal muscle $(1,11,19,26,46,54,76,77)$, which has been shown in cell culture (1), in metabolically normal $(11,76,77)$, obese $(54)$, and insulin resistant $(19,46,64)$ animals, and in humans (26). In several cases this improvement is associated with reduced plasma and intramyocellular lipid levels $(11,46,54,68,86)$, indicating reduced lipid flux to tissues and either reduced TG synthesis or increased FA oxidation. AMPK-activating treatments are also established to improve glucose and lipid homeostasis and enhance insulin sensitivity $(17,29,30$, $44,56,72)$. However, there is limited literature examining the cellular effects of marine n-3 PUFAs on AMPK, especially in skeletal muscle. AMPK is an important sensor of cellular lipid status $(90,94)$ and regulator of FA oxidative metabolism $(47,92,94)$ and mitochondrial biogenesis (62). Furthermore, omega PUFAs have been identified to partition FA from storage toward oxidation in liver and skeletal muscle (6). Therefore, it is possible that marine n-3 PUFAs exert positive effects on AMPK phosphorylation, which leads to improvements in FA oxidation and possibly mitochondrial oxidative capacity to reduce intramyocellular lipid storage. There has been no published research to date examining the effects of marine n-3 PUFAs on pAMPK in skeletal muscle cell culture, although the outcomes of other FA treatments on AMPK activity have been examined $(15,92)$. Furthermore, only two in vivo studies have examined the 
effects of marine n-3 PUFAs on AMPK, with one in liver (78) and the other in skeletal muscle (13).

Male Sprague-Dawley rats were fed an initial 7-day high-glucose, no fat diet, which decreased liver p-AMPK ${ }^{\text {Thr172 }}$ levels and AMPK activity by $80 \%$ and approximately $50 \%$, respectively, versus pre-meal values, with similar reductions in p-ACC levels and no change in total AMPK protein concentration. This is not unexpected, as the same group demonstrated a depression in AMPK phosphorylation and activity with re-feeding a high-carbohydrate diet after fasting (2). For the next 7 days, rats were fed the same high-glucose diet but supplemented with 10 grams of either MUFA [triolein, 99\% omega-9] or PUFA [35\% EPA and DHA] per 100 grams of diet. Fasted p-AMPK $\alpha^{\text {Thr172 }}$ values were unchanged, while p-AMPK $^{\text {Thr172 }}$ and p$\mathrm{ACC} \beta^{\mathrm{Ser} 79}$ levels were reduced with both diets 2 hours following the final meal. However, this reduction was greater with the MUFA diet than the PUFA diet, as both postprandial PUFA p$\mathrm{AMPK}^{\mathrm{Thr} 172}$ and p-ACC levels were approximately double MUFA levels. Furthermore, MUFA feeding was associated with significantly lower AMPK activity levels than PUFA feeding (78). This indicates that although AMPK was not affected in the post-absorptive state, n-3 PUFAs did exert a greater activating effect on AMPK and ACC phosphorylation and AMPK activity than MUFAs. Moreover, the PUFA group demonstrated lower postprandial levels of fatty acid synthase (FAS) mRNA and higher CPT-1 mRNA expression than the MUFA group (78), indicating a greater shift from lipogenesis toward FA oxidation with n-3 PUFA feeding.

While any FA treatment could be expected to upregulate levels of AMPK activity, phosphorylated AMPK and ACC, FA transport proteins, and oxidative enzymes after a highglucose, no-fat diet, merely due to their renewed presence in the tissues, an n-3 PUFA treatment was more effective than a MUFA treatment in doing so. This is promising because it suggests that mechanism(s) other than simply the law of mass action contribute to the ability of n-3 PUFAs to activate AMPK and ACC. Whether they may do this directly by acting on AMPK or indirectly by acting on upstream AMPK regulators still needs to be determined. Furthermore, this study is considered short-term (46) because the MUFA and PUFA supplements were administered for only one week, and it would be interesting to observe the chronic effects of n-3 PUFA feeding on AMPK activity, especially in relation to any alterations in systemic insulin sensitivity. 
In response to this study, Dobrzyn et al. (13) evaluated the effects of feeding a 5\% fat diet of either PUFA from FO or MUFA from triolein for 14 days on AMPK activity in heart, liver, and skeletal muscle of mice. They found no changes in p-AMPK ${ }^{\text {Thr172 }}$ levels in FO-fed animals versus control in any tissue (13). While these results suggest that PUFAs do not activate AMPK in mouse tissues, no changes were observed in liver p-AMPK ${ }^{\text {Thr172 }}$, which is contradictory to the previous findings (78) that n-3 PUFAs are more effective in stimulating liver AMPK than MUFAs and indicates that confounding factors may be present. For one, these animals were metabolically challenged with stearoyl-CoA desaturase 1-deficiency, making the results difficult to compare to other studies in metabolically normal animals. Additionally, this PUFA diet contained $5 \%$ fat with $25 \% \mathrm{EPA} / \mathrm{DHA}$ content, versus $10 \%$ fat and $35 \% \mathrm{EPA} / \mathrm{DHA}$ content in the study by Suchankova et al. (78), indicating that the n-3 PUFA composition of the diet may not have been great enough to observe positive effects on AMPK activity.

HF-feeding was shown to reduce skeletal muscle AMPK phosphorylation and activity, which correlated with reductions in systemic insulin sensitivity (44). Additionally, administration of marine n-3 PUFAs attenuated reductions in p-AMPK, p-ACC, and CPT-1 mRNA and increased suppression of FAS in the liver of normal animals (78). These data prompt further investigation of the effects of marine n-3 PUFAs on skeletal muscle AMPK phosphorylation and activity to identify if the improvement in insulin sensitivity observed with n-3 supplementation is at all related to improvement in FA oxidation and reduction in intramyocellular lipid content. 


\section{Reference List}

1. Aas V, Rokling-Andersen MH, Kase ET, Thoresen GH, and Rustan AC. Eicosapentaenoic acid $(20: 5 n-3)$ increases fatty acid and glucose uptake in cultured human skeletal muscle cells. $J$ Lipid Res 47: 366-374, 2006.

2. Assifi MM, Suchankova G, Constant S, Prentki M, Saha AK, and Ruderman NB. AMPactivated protein kinase and coordination of hepatic fatty acid metabolism of starved/carbohydrate-refed rats. American journal of physiology 289: E794-800, 2005.

3. Barnes BR, Marklund S, Steiler TL, Walter M, Hjalm G, Amarger V, Mahlapuu M, Leng Y, Johansson C, Galuska D, Lindgren K, Abrink M, Stapleton D, Zierath JR, and Andersson L. The 5'-AMP-activated protein kinase gamma3 isoform has a key role in carbohydrate and lipid metabolism in glycolytic skeletal muscle. J Biol Chem 279: 38441-38447, 2004.

4. Barnes BR, and Zierath JR. Role of AMP--activated protein kinase in the control of glucose homeostasis. Curr Mol Med 5: 341-348, 2005.

5. Chanseaume E, Giraudet C, Gryson C, Walrand S, Rousset P, Boirie Y, and Morio B. Enhanced muscle mixed and mitochondrial protein synthesis rates after a high-fat or highsucrose diet. Obesity (Silver Spring) 15: 853-859, 2007.

6. Clarke SD. Polyunsaturated fatty acid regulation of gene transcription: a molecular mechanism to improve the metabolic syndrome. J Nutr 131: 1129-1132, 2001.

7. Coll T, Eyre E, Rodriguez-Calvo R, Palomer X, Sanchez RM, Merlos M, Laguna JC, and Vazquez-Carrera $\mathbf{M}$. Oleate reverses palmitate-induced insulin resistance and inflammation in skeletal muscle cells. J Biol Chem 2008.

8. Coll T, Jove M, Rodriguez-Calvo R, Eyre E, Palomer X, Sanchez RM, Merlos M, Laguna JC, and Vazquez-Carrera M. Palmitate-mediated downregulation of peroxisome proliferatoractivated receptor-gamma coactivator 1alpha in skeletal muscle cells involves MEK1/2 and nuclear factor-kappaB activation. Diabetes 55: 2779-2787, 2006.

9. Cuthbertson DJ, Babraj JA, Mustard KJ, Towler MC, Green KA, Wackerhage H, Leese GP, Baar K, Thomason-Hughes M, Sutherland C, Hardie DG, and Rennie MJ. 5-aminoimidazole4-carboxamide 1-beta-D-ribofuranoside acutely stimulates skeletal muscle 2-deoxyglucose uptake in healthy men. Diabetes 56: 2078-2084, 2007.

10. D'Alessandro ME, Chicco A, Karabatas L, and Lombardo YB. Role of skeletal muscle on impaired insulin sensitivity in rats fed a sucrose-rich diet: effect of moderate levels of dietary fish oil. J Nutr Biochem 11: 273-280, 2000.

11. D'Alessandro ME, Lombardo YB, and Chicco A. Effect of dietary fish oil on insulin sensitivity and metabolic fate of glucose in the skeletal muscle of normal rats. Ann Nutr Metab 46: 114-120, 2002.

12. Das UN. Essential fatty acids: biochemistry, physiology and pathology. Biotechnol J 1: 420-439, 2006.

13. Dobrzyn A, Dobrzyn P, Miyazaki M, and Ntambi JM. Polyunsaturated fatty acids do not activate AMP-activated protein kinase in mouse tissues. Biochem Biophys Res Commun 332: 892-896, 2005.

14. Faergeman NJ, and Knudsen J. Role of long-chain fatty acyl-CoA esters in the regulation of metabolism and in cell signalling. Biochem J 323 ( Pt 1): 1-12, 1997.

15. Fediuc S, Gaidhu MP, and Ceddia RB. Regulation of AMP-activated protein kinase and acetylCoA carboxylase phosphorylation by palmitate in skeletal muscle cells. J Lipid Res 47: 412-420, 2006.

16. Fediuc S, Pimenta AS, Gaidhu MP, and Ceddia RB. Activation of AMP-activated protein kinase, inhibition of pyruvate dehydrogenase activity, and redistribution of substrate partitioning mediate the acute insulin-sensitizing effects of troglitazone in skeletal muscle cells. J Cell Physiol 215: 392-400, 2007.

17. Fisher JS, Gao J, Han DH, Holloszy JO, and Nolte LA. Activation of AMP kinase enhances sensitivity of muscle glucose transport to insulin. American journal of physiology 282: E18-23, 2002. 
18. Gaidhu MP, Fediuc S, and Ceddia RB. 5-Aminoimidazole-4-carboxamide-1-beta-Dribofuranoside-induced AMP-activated protein kinase phosphorylation inhibits basal and insulinstimulated glucose uptake, lipid synthesis, and fatty acid oxidation in isolated rat adipocytes. $J$ Biol Chem 281: 25956-25964, 2006.

19. Ghafoorunissa, Ibrahim A, Rajkumar L, and Acharya V. Dietary (n-3) long chain polyunsaturated fatty acids prevent sucrose-induced insulin resistance in rats. J Nutr 135: 26342638, 2005.

20. Gingras AA, White PJ, Chouinard PY, Julien P, Davis TA, Dombrowski L, Couture Y, Dubreuil P, Myre A, Bergeron K, Marette A, and Thivierge MC. Long-chain omega-3 fatty acids regulate bovine whole-body protein metabolism by promoting muscle insulin signalling to the Akt-mTOR-S6K1 pathway and insulin sensitivity. J Physiol 579: 269-284, 2007.

21. Gregg EW, Cheng YJ, Narayan KM, Thompson TJ, and Williamson DF. The relative contributions of different levels of overweight and obesity to the increased prevalence of diabetes in the United States: 1976-2004. Prev Med 45: 348-352, 2007.

22. Guo ZK. Intramyocellular lipid kinetics and insulin resistance. Lipids Health Dis 6: 18, 2007.

23. Hardie DG. Biochemistry. Balancing cellular energy. Science 315: 1671-1672, 2007.

24. Hardie DG. Minireview: the AMP-activated protein kinase cascade: the key sensor of cellular energy status. Endocrinology 144: 5179-5183, 2003.

25. Hardy LR, Harrell JS, and Bell RA. Overweight in children: definitions, measurements, confounding factors, and health consequences. J Pediatr Nurs 19: 376-384, 2004.

26. Haugaard SB, Madsbad S, Hoy CE, and Vaag A. Dietary intervention increases n-3 long-chain polyunsaturated fatty acids in skeletal muscle membrane phospholipids of obese subjects. Implications for insulin sensitivity. Clin Endocrinol (Oxf) 64: 169-178, 2006.

27. Horman S, Vertommen D, Heath R, Neumann D, Mouton V, Woods A, Schlattner U, Wallimann T, Carling D, Hue L, and Rider MH. Insulin antagonizes ischemia-induced Thr172 phosphorylation of AMP-activated protein kinase alpha-subunits in heart via hierarchical phosphorylation of Ser485/491. J Biol Chem 281: 5335-5340, 2006.

28. Hurley RL, Anderson KA, Franzone JM, Kemp BE, Means AR, and Witters LA. The $\mathrm{Ca} 2+$ /calmodulin-dependent protein kinase kinases are AMP-activated protein kinase kinases. $J$ Biol Chem 280: 29060-29066, 2005.

29. Iglesias MA, Furler SM, Cooney GJ, Kraegen EW, and Ye JM. AMP-activated protein kinase activation by AICAR increases both muscle fatty acid and glucose uptake in white muscle of insulin-resistant rats in vivo. Diabetes 53: 1649-1654, 2004.

30. Iglesias MA, Ye JM, Frangioudakis G, Saha AK, Tomas E, Ruderman NB, Cooney GJ, and Kraegen EW. AICAR administration causes an apparent enhancement of muscle and liver insulin action in insulin-resistant high-fat-fed rats. Diabetes 51: 2886-2894, 2002.

31. Iossa S, Mollica MP, Lionetti L, Crescenzo R, Botta M, and Liverini G. Skeletal muscle oxidative capacity in rats fed high-fat diet. Int J Obes Relat Metab Disord 26: 65-72, 2002.

32. Jager S, Handschin C, St-Pierre J, and Spiegelman BM. AMP-activated protein kinase (AMPK) action in skeletal muscle via direct phosphorylation of PGC-1alpha. Proc Natl Acad Sci U S A 104: 12017-12022, 2007.

33. Jin UH, Kang YJ, Chang YC, and Kim CH. Secretion of atherogenic risk factor apolipoprotein B100 is increased by a potential mechanism of JNK/PKC-mediated insulin resistance in liver cells. Journal of cellular biochemistry 103: 908-919, 2008.

34. Jump DB, and Clarke SD. Regulation of gene expression by dietary fat. Annu Rev Nutr 19: 6390, 1999.

35. Kokta TA, Dodson MV, Gertler A, and Hill RA. Intercellular signaling between adipose tissue and muscle tissue. Domest Anim Endocrinol 27: 303-331, 2004.

36. Koshinaka K, Oshida Y, Han YQ, Kubota M, Viana AY, Nagasaki M, and Sato Y. Insulinnonspecific reduction in skeletal muscle glucose transport in high-fat-fed rats. Metabolism 53: 912-917, 2004.

37. Krook A, Wallberg-Henriksson $\mathbf{H}$, and Zierath JR. Sending the signal: molecular mechanisms regulating glucose uptake. Med Sci Sports Exerc 36: 1212-1217, 2004.

38. Le Foll C, Corporeau C, Le Guen V, Gouygou JP, Berge JP, and Delarue J. Long-chain n-3 polyunsaturated fatty acids dissociate phosphorylation of Akt from phosphatidylinositol 3'-kinase activity in rats. American journal of physiology 292: E1223-1230, 2007. 
39. Lee JS, Pinnamaneni SK, Eo SJ, Cho IH, Pyo JH, Kim CK, Sinclair AJ, Febbraio MA, and Watt MJ. Saturated, but not $n-6$ polyunsaturated, fatty acids induce insulin resistance: role of intramuscular accumulation of lipid metabolites. J Appl Physiol 100: 1467-1474, 2006.

40. Lee WJ, Kim M, Park HS, Kim HS, Jeon MJ, Oh KS, Koh EH, Won JC, Kim MS, Oh GT, Yoon M, Lee KU, and Park JY. AMPK activation increases fatty acid oxidation in skeletal muscle by activating PPARalpha and PGC-1. Biochem Biophys Res Commun 340: 291-295, 2006.

41. Listenberger LL, Han X, Lewis SE, Cases S, Farese RV, Jr., Ory DS, and Schaffer JE. Triglyceride accumulation protects against fatty acid-induced lipotoxicity. Proc Natl Acad Sci U S A 100: 3077-3082, 2003.

42. Liu L, Zhang Y, Chen N, Shi X, Tsang B, and Yu YH. Upregulation of myocellular DGAT1 augments triglyceride synthesis in skeletal muscle and protects against fat-induced insulin resistance. J Clin Invest 117: 1679-1689, 2007.

43. Liu S, Baracos VE, Quinney HA, and Clandinin MT. Dietary omega-3 and polyunsaturated fatty acids modify fatty acyl composition and insulin binding in skeletal-muscle sarcolemma. Biochem J 299 ( Pt 3): 831-837, 1994.

44. Liu Y, Wan Q, Guan Q, Gao L, and Zhao J. High-fat diet feeding impairs both the expression and activity of AMPKa in rats' skeletal muscle. Biochem Biophys Res Commun 339: 701-707, 2006.

45. Lombardo YB, and Chicco AG. Effects of dietary polyunsaturated n-3 fatty acids on dyslipidemia and insulin resistance in rodents and humans. A review. J Nutr Biochem 17: 1-13, 2006.

46. Lombardo YB, Hein G, and Chicco A. Metabolic syndrome: effects of n-3 PUFAs on a model of dyslipidemia, insulin resistance and adiposity. Lipids 42: 427-437, 2007.

47. Long YC, and Zierath JR. AMP-activated protein kinase signaling in metabolic regulation. J Clin Invest 116: 1776-1783, 2006.

48. Madsen L, Pedersen LM, Liaset B, Ma T, Petersen RK, van den Berg S, Pan J, MullerDecker K, Dulsner ED, Kleemann R, Kooistra T, Doskeland SO, and Kristiansen K. cAMPdepending signaling regulates the adipogenic effect of $\mathrm{N}-6$ polyunsaturated fatty acids. $\mathrm{J}$ Biol Chem 2007.

49. Martin TL, Alquier T, Asakura K, Furukawa N, Preitner F, and Kahn BB. Diet-induced obesity alters AMP kinase activity in hypothalamus and skeletal muscle. J Biol Chem 281: 18933-18941, 2006.

50. Mensink M, Blaak EE, Vidal H, De Bruin TW, Glatz JF, and Saris WH. Lifestyle changes and lipid metabolism gene expression and protein content in skeletal muscle of subjects with impaired glucose tolerance. Diabetologia 46: 1082-1089, 2003.

51. Minokoshi Y, Kim YB, Peroni OD, Fryer LG, Muller C, Carling D, and Kahn BB. Leptin stimulates fatty-acid oxidation by activating AMP-activated protein kinase. Nature 415: 339-343, 2002.

52. Montell E, Turini M, Marotta M, Roberts M, Noe V, Ciudad CJ, Mace K, and Gomez-Foix AM. DAG accumulation from saturated fatty acids desensitizes insulin stimulation of glucose uptake in muscle cells. American journal of physiology 280: E229-237, 2001.

53. Morino K, Petersen KF, Dufour S, Befroy D, Frattini J, Shatzkes N, Neschen S, White MF, Bilz S, Sono S, Pypaert M, and Shulman GI. Reduced mitochondrial density and increased IRS-1 serine phosphorylation in muscle of insulin-resistant offspring of type 2 diabetic parents. $J$ Clin Invest 115: 3587-3593, 2005.

54. Mustad VA, Demichele S, Huang YS, Mika A, Lubbers N, Berthiaume N, Polakowski J, and Zinker B. Differential effects of n-3 polyunsaturated fatty acids on metabolic control and vascular reactivity in the type 2 diabetic ob/ob mouse. Metabolism 55: 1365-1374, 2006.

55. Ogden CL, Carroll MD, Curtin LR, McDowell MA, Tabak CJ, and Flegal KM. Prevalence of overweight and obesity in the United States, 1999-2004. Jama 295: 1549-1555, 2006.

56. Olsen GS, and Hansen BF. AMP kinase activation ameliorates insulin resistance induced by free fatty acids in rat skeletal muscle. American journal of physiology 283: E965-970, 2002.

57. Ostergard T, Andersen JL, Nyholm B, Lund S, Nair KS, Saltin B, and Schmitz O. Impact of exercise training on insulin sensitivity, physical fitness, and muscle oxidative capacity in firstdegree relatives of type 2 diabetic patients. American journal of physiology 290: E998-1005, 2006. 
58. Passi S, Cataudella S, Di Marco P, De Simone F, and Rastrelli L. Fatty acid composition and antioxidant levels in muscle tissue of different Mediterranean marine species of fish and shellfish. J Agric Food Chem 50: 7314-7322, 2002.

59. Pickersgill L, Litherland GJ, Greenberg AS, Walker M, and Yeaman SJ. Key role for ceramides in mediating insulin resistance in human muscle cells. J Biol Chem 282: 12583-12589, 2007.

60. Pruchnic R, Katsiaras A, He J, Kelley DE, Winters C, and Goodpaster BH. Exercise training increases intramyocellular lipid and oxidative capacity in older adults. American journal of physiology 287: E857-862, 2004.

61. Qiang W, Weiqiang K, Qing Z, Pengju Z, and Yi L. Aging impairs insulin-stimulated glucose uptake in rat skeletal muscle via suppressing AMPKalpha. Exp Mol Med 39: 535-543, 2007.

62. Reznick RM, Zong H, Li J, Morino K, Moore IK, Yu HJ, Liu ZX, Dong J, Mustard KJ, Hawley SA, Befroy D, Pypaert M, Hardie DG, Young LH, and Shulman GI. Aging-associated reductions in AMP-activated protein kinase activity and mitochondrial biogenesis. Cell Metab 5: 151-156, 2007.

63. Rimbert V, Boirie Y, Bedu M, Hocquette JF, Ritz P, and Morio B. Muscle fat oxidative capacity is not impaired by age but by physical inactivity: association with insulin sensitivity. Faseb $\mathrm{J} 18$ : 737-739, 2004.

64. Rossi AS, Lombardo YB, Lacorte JM, Chicco AG, Rouault C, Slama G, and Rizkalla SW. Dietary fish oil positively regulates plasma leptin and adiponectin levels in sucrose-fed, insulinresistant rats. Am J Physiol Regul Integr Comp Physiol 289: R486-R494, 2005.

65. Sabin MA, Stewart CE, Crowne EC, Turner SJ, Hunt LP, Welsh GI, Grohmann MJ, Holly JM, and Shield JP. Fatty acid-induced defects in insulin signalling, in myotubes derived from children, are related to ceramide production from palmitate rather than the accumulation of intramyocellular lipid. J Cell Physiol 211: 244-252, 2007.

66. Sampath $\mathbf{H}$, and Ntambi JM. Polyunsaturated fatty acid regulation of gene expression. Nutr Rev 62: 333-339, 2004.

67. Schrauwen P. High-fat diet, muscular lipotoxicity and insulin resistance. Proc Nutr Soc 66: 33-41, 2007.

68. Simoncikova P, Wein S, Gasperikova D, Ukropec J, Certik M, Klimes I, and Sebokova E. Comparison of the extrapancreatic action of gamma-linolenic acid and n-3 PUFAs in the high fat diet-induced insulin resistance [corrected]. Endocr Regul 36: 143-149, 2002.

69. Siu PM, Donley DA, Bryner RW, and Alway SE. Citrate synthase expression and enzyme activity after endurance training in cardiac and skeletal muscles. J Appl Physiol 94: 555-560, 2003.

70. Siu PM, Donley DA, Bryner RW, and Alway SE. Myogenin and oxidative enzyme gene expression levels are elevated in rat soleus muscles after endurance training. $J$ Appl Physiol 97: 277-285, 2004.

71. Smith AC, Mullen KL, Junkin KA, Nickerson J, Chabowski A, Bonen A, and Dyck DJ. Metformin and exercise reduce muscle FAT/CD36 and lipid accumulation and blunt the progression of high-fat diet-induced hyperglycemia. American journal of physiology 293: E172181, 2007.

72. Song XM, Fiedler M, Galuska D, Ryder JW, Fernstrom M, Chibalin AV, Wallberg-Henriksson H, and Zierath JR. 5-Aminoimidazole-4-carboxamide ribonucleoside treatment improves glucose homeostasis in insulin-resistant diabetic (ob/ob) mice. Diabetologia 45: 56-65, 2002.

73. Steinberg GR. Inflammation in obesity is the common link between defects in fatty acid metabolism and insulin resistance. Cell Cycle 6: 888-894, 2007.

74. Steinberg GR, and Jorgensen SB. The AMP-activated protein kinase: role in regulation of skeletal muscle metabolism and insulin sensitivity. Mini Rev Med Chem 7: 519-526, 2007.

75. Steinberg GR, Macaulay SL, Febbraio MA, and Kemp BE. AMP-activated protein kinase--the fat controller of the energy railroad. Can J Physiol Pharmacol 84: 655-665, 2006.

76. Storlien LH, Jenkins AB, Chisholm DJ, Pascoe WS, Khouri S, and Kraegen EW. Influence of dietary fat composition on development of insulin resistance in rats. Relationship to muscle triglyceride and omega-3 fatty acids in muscle phospholipid. Diabetes 40: 280-289, 1991.

77. Storlien LH, Kraegen EW, Chisholm DJ, Ford GL, Bruce DG, and Pascoe WS. Fish oil prevents insulin resistance induced by high-fat feeding in rats. Science 237: 885-888, 1987. 
78. Suchankova G, Tekle M, Saha AK, Ruderman NB, Clarke SD, and Gettys TW. Dietary polyunsaturated fatty acids enhance hepatic AMP-activated protein kinase activity in rats. Biochem Biophys Res Commun 326: 851-858, 2005.

79. Suwa M, Egashira T, Nakano H, Sasaki H, and Kumagai S. Metformin increases the PGC1alpha protein and oxidative enzyme activities possibly via AMPK phosphorylation in skeletal muscle in vivo. J Appl Physiol 101: 1685-1692, 2006.

80. Suzuki A, Okamoto S, Lee S, Saito K, Shiuchi T, and Minokoshi Y. Leptin stimulates fatty acid oxidation and peroxisome proliferator-activated receptor alpha gene expression in mouse $\mathrm{C} 2 \mathrm{C} 12$ myoblasts by changing the subcellular localization of the alpha2 form of AMP-activated protein kinase. Mol Cell Biol 27: 4317-4327, 2007.

81. Taouis M, Dagou C, Ster C, Durand G, Pinault M, and Delarue J. N-3 polyunsaturated fatty acids prevent the defect of insulin receptor signaling in muscle. American journal of physiology 282: E664-671, 2002.

82. Taugbol O, and Saarem K. Fatty acid composition of porcine muscle and adipose tissue lipids as affected by anatomical location and cod liver oil supplementation of the diet. Acta Vet Scand 36: 93-101, 1995.

83. Taylor EB, Ellingson WJ, Lamb JD, Chesser DG, and Winder WW. Long-chain acyl-CoA esters inhibit phosphorylation of AMP-activated protein kinase at threonine-172 by

LKB1/STRAD/MO25. American journal of physiology 288: E1055-1061, 2005.

84. Towler MC, and Hardie DG. AMP-activated protein kinase in metabolic control and insulin signaling. Circ Res 100: 328-341, 2007.

85. Turner N, Bruce CR, Beale SM, Hoehn KL, So T, Rolph MS, and Cooney GJ. Excess lipid availability increases mitochondrial fatty acid oxidative capacity in muscle: evidence against a role for reduced fatty acid oxidation in lipid-induced insulin resistance in rodents. Diabetes 56: 20852092, 2007.

86. Ukropec J, Reseland JE, Gasperikova D, Demcakova E, Madsen L, Berge RK, Rustan AC, Klimes I, Drevon CA, and Sebokova E. The hypotriglyceridemic effect of dietary n-3 FA is associated with increased beta-oxidation and reduced leptin expression. Lipids 38: 1023-1029, 2003.

87. Unger RH. Minireview: weapons of lean body mass destruction: the role of ectopic lipids in the metabolic syndrome. Endocrinology 144: 5159-5165, 2003.

88. Unger RH, and Orci L. Lipoapoptosis: its mechanism and its diseases. Biochim Biophys Acta 1585: 202-212, 2002.

89. Vaarmann A, Fortin D, Veksler V, Momken I, Ventura-Clapier R, and Garnier A. Mitochondrial biogenesis in fast skeletal muscle of CK deficient mice. Biochim Biophys Acta 1777: 39-47, 2008.

90. Wang X, Zhou L, Li G, Luo T, Gu Y, Qian L, Fu X, Li F, Li J, and Luo M. Palmitate activates AMP-activated protein kinase and regulates insulin secretion from beta cells. Biochem Biophys Res Commun 352: 463-468, 2007.

91. Watson RT, and Pessin JE. Bridging the GAP between insulin signaling and GLUT4 translocation. Trends Biochem Sci 31: 215-222, 2006.

92. Watt MJ, Steinberg GR, Chen ZP, Kemp BE, and Febbraio MA. Fatty acids stimulate AMPactivated protein kinase and enhance fatty acid oxidation in L6 myotubes. $J$ Physiol 574: 139-147, 2006.

93. Winder WW, Holmes BF, Rubink DS, Jensen EB, Chen M, and Holloszy JO. Activation of AMP-activated protein kinase increases mitochondrial enzymes in skeletal muscle. J Appl Physiol 88: 2219-2226, 2000.

94. Wu Y, Song $\mathbf{P}, \mathbf{X u} \mathbf{J}$, Zhang $\mathbf{M}$, and Zou MH. Activation of protein phosphatase 2A by palmitate inhibits AMP-activated protein kinase. J Biol Chem 282: 9777-9788, 2007.

95. Yam D, Eliraz A, and Berry EM. Diet and disease--the Israeli paradox: possible dangers of a high omega-6 polyunsaturated fatty acid diet. Isr J Med Sci 32: 1134-1143, 1996.

96. Yoon MJ, Lee GY, Chung JJ, Ahn YH, Hong SH, and Kim JB. Adiponectin increases fatty acid oxidation in skeletal muscle cells by sequential activation of AMP-activated protein kinase, p38 mitogen-activated protein kinase, and peroxisome proliferator-activated receptor alpha. Diabetes 55: 2562-2570, 2006. 
97. Yu X, McCorkle S, Wang M, Lee Y, Li J, Saha AK, Unger RH, and Ruderman NB. Leptinomimetic effects of the AMP kinase activator AICAR in leptin-resistant rats: prevention of diabetes and ectopic lipid deposition. Diabetologia 47: 2012-2021, 2004.

98. Zick Y. Role of Ser/Thr kinases in the uncoupling of insulin signaling. Int J Obes Relat Metab Disord 27 Suppl 3: S56-60, 2003. 


\section{CHAPTER 3. RESEARCH METHODS}

Materials. Mouse $\mathrm{C} 2 \mathrm{C} 12$ myoblasts were purchased from American Type Culture Collection. Fetal calf serum (FCS) was purchased from Atlas Biologicals. ITS Liquid Media Supplement, palmitic acid sodium salt, cis-4, 7, 10, 13, 16, 19-docosahexaenoic acid (DHA) oil, insulin, Ponceau S red, 99\% triethyl phosphate, and a citrate synthase assay kit (Cat\# CS0720) were purchased from Sigma. BSA was purchased from Santa Cruz Biotechnology. SDS-PAGE precast gels were purchased from Invitrogen, and nitrocellulose membranes and an $R C D C$ protein assay kit (\#500-0121) were purchased from BioRad. Antibodies were purchased from Cell Signaling Technology, and goat anti-rabbit and goat anti-mouse horseradish peroxidaseconjugated IgG were purchased from Jackson ImmunoResearch Laboratories, Inc.. Enhanced chemiluminescence (ECL) was purchased from Pierce, and advanced ECL was purchased from Amersham Biosciences. ReBlot Plus Strong Solution was purchased from Millipore. X-ray film was purchased from Phenix Research Products. Oil Red O powder was purchased from Fluka Analytical.

Cell culture. Mouse $\mathrm{C}_{2} \mathrm{C}_{12}$ myoblasts were seeded in six-well (35-mm) plates in DMEM (4.5 g/L D-glucose, with L-glutamine, pyridoxine hydrochloride, $110 \mathrm{mg} / \mathrm{L}$ sodium pyruvate, and $3.7 \mathrm{~g} / \mathrm{L}$ sodium bicarbonate) supplemented with $10 \%$ FCS and $1 \%$ penicillin and streptomycin (PS) and maintained in a humidified incubator at $37^{\circ} \mathrm{C}$ in an atmosphere of $5 \% \mathrm{CO}_{2}$. Cells were grown to $\sim 95 \%$ confluence and then induced to differentiate into myotubes by incubation in serum- and PS-free DMEM supplemented with 1\% ITS Liquid Media Supplement for 3 days. After differentiation, cells were maintained in DMEM with 2\% FCS until experimental treatment.

Palmitate and cis-4, 7, 10, 13, 16, 19-docosahexaenoic acid (DHA) oil were dissolved in ethanol and diluted in DMEM containing 2\% BSA to reach desired fatty acid (FA) concentrations. For dose-response experiments, myotubes were treated separately with palmitate and DHA in $0 \mathrm{mM}, 0.1 \mathrm{mM}, 0.25 \mathrm{mM}, 0.5 \mathrm{mM}, 0.75 \mathrm{mM}$, and $1.0 \mathrm{mM}$ concentrations in media containing 2\% FCS, and 2\% BSA for 24 hours. For time-response experiments, myotubes were treated with media containing $2 \% \mathrm{FCS}, 2 \% \mathrm{BSA}$, and $0.5 \mathrm{mM}$ palmitate or $0.1 \mathrm{mM}$ DHA for 24 , 48, and 96 hours. For all subsequent experiments, myotubes were treated with media containing $2 \% \mathrm{FCS}, 2 \% \mathrm{BSA}$, and $0.5 \mathrm{mM}$ palmitate, $0.1 \mathrm{mM}$ DHA, $0.5 \mathrm{mM}$ palmitate plus $0.1 \mathrm{mM}$ DHA, or 
no FA for 96 hours, and fresh media was provided every 48 hours. For insulin-stimulation experiments, myotubes were washed once with PBS and treated with 100nM insulin in DMEM for 15 minutes.

Image capture and cell size. Images from myotubes that were treated for 48 and 96 hours were visualized at X20 magnification using an inverted light microscope (Nikon) and captured with a Spot RT camera and Spot Software (Diagnostic Instruments). Myotube diameter was measured from randomly selected microscope fields from three different wells $(35 \mathrm{~mm})$ of control and treated conditions (12 wells total per time-point) using Image $J$ software (37). Six diameters were measured per myotube, and ten myotubes were measured per well, except in the case of palmitate-treated cells, where if ten myotubes were not present, all of the remaining myotubes were measured.

Evaluation of phosphorylated and total proteins. Cells were harvested by scraping in 1 x SDS sample buffer (1\% SDS, $6 \mathrm{mg} / \mathrm{mL}$ EDTA, $0.06 \mathrm{M}$ Tris (hydroxymethyl) aminomethane (pH 6.8), $2 \mathrm{mg} / \mathrm{mL}$ bromophenol blue, $15 \%$ glycerol, and $5 \% \beta$-mercaptoethanol). Protein concentrations were quantified in duplicate using an $R C D C$ protein assay and averaged for determination of Western blot loading volumes. Aliquots $(30 \mu \mathrm{g} / \mathrm{ml})$ of harvested $\mathrm{C}_{2} \mathrm{C}_{12}$ cells were resolved by $10 \%, 3-8 \%$, or $4-12 \%$ SDS-PAGE using pre-cast gels. Control and treated cells were loaded on the same gel to account for possible variations between blots, as well as a standard molecular weight marker to verify protein sizes. Proteins were transferred to a nitrocellulose membrane and stained with Ponceau S red to confirm transfer. Membranes were probed with primary antibodies against phosphorylated T172 for AMPKa, S79 for ACC, S636/639 for IRS-1, S473 for Akt, S21/9 for GSK3 $\alpha / \beta$, S240/244 for rpS6, or for total protein expression of PGC1 $\alpha$ and COX-IV. Membranes were then probed with anti-species conjugated horseradish peroxidase secondary antibodies. Blots were developed as described below. Where appropriate, membranes were stripped with 1X ReBlot Plus Strong Solution and probed with antibodies against total protein expression of AMPK $\alpha$, ACC, Akt, GSK3 $\beta, \beta$-tubulin, and GAPDH. Signals for GAPDH were developed by enhanced chemiluminescence and for all other proteins by advanced ECL, and bands were visualized by exposing the membranes X-ray film. Digital records of the films were captured with a Kodak 290 camera, and bands were quantified as 
optical density $\mathrm{x}$ band area by a one-dimensional image analysis system (Eastman Kodak) and expressed in arbitrary units normalized relative to the loading control.

Oil red $\boldsymbol{O}$ stain. Oil Red O (ORO) staining was performed as a visual marker to evaluate the effects of FA treatments on intramyocellular lipid content after 48 and 96 hours (15). Cells were grown, differentiated, and treated with FA as previously described. A 5g/L ORO stock solution was prepared in a 3:2 ratio of 99\% triethyl phosphate to distilled water. For staining, the stock solution was diluted to a $36 \%$ ORO/TEP working solution then filtered three times by passing through a syringe with a 0.45 micron filter tip. Culture dishes were washed three times with PBS and myotubes fixed with $10 \%$ formalin then washed with distilled water and stained with $36 \%$ ORO/TEP. Stained myotubes were rinsed with distilled water and visualized. Intramyocellular lipid content was quantified by measuring fluorescence (excitation $485 \mathrm{~nm}$, emission $530 \mathrm{~nm}$ ) of the stained lipids, and values were normalized to protein content per well, which was determined using a commercially available kit.

Citrate Synthase Activity. To evaluate the effects of FA treatments on mitochondria oxidative metabolism after 96 hours, the activity level of citrate synthase (CS) was evaluated using an assay kit according to the manufacturer's instructions. Cells were grown, differentiated, and treated with FA as previously described. Cells were lysed in $200 \mu \mathrm{L}$ of CelLytic M Reagent, centrifuged at 12,000 $\mathrm{x} g$, and the supernatant transferred to a chilled test tube. Protein content was determined as described previously. The sample reaction mixture was prepared with the appropriate volumes of $1 \mathrm{x}$ Assay Buffer, $30 \mathrm{mM}$ Acetyl CoA Solution, and $10 \mathrm{mM}$ DTNB solution and added to $10 \mu \mathrm{L}$ of sample in a 96 -well plate. The spectrophotometer was set at 412 $\mathrm{nm}$, and absorbances were measured at 0,1 , and 2 minutes. After determining the baseline absorbance of the reaction mixture for 2 minutes, $10 \mathrm{mM}$ Oxaloacetate Solution was added to the reaction, and the absorbance was read for another 2 minutes to determine total CS activity. All samples were evaluated in triplicate. CS activity for each sample was calculated per manufacturer instructions and was normalized to protein content. A CS positive control was included for each experiment. 
Statistical Analyses. All results represent the mean percent change \pm standard error for a minimum of three cell culture experiments $(n=3)$ in triplicate, with exception to insulinstimulation experiments which consists of two experiments $(n=2)$ in triplicate. One-way ANOVA with Tukey post-hoc analysis was used to evaluate differences for each variable between treatments, and statistical significance was set at $P \leq 0.05$. Analyses were conducted using SPSS 12.0.1 software package. 


\section{CHAPTER 4. RESULTS}

Selection of fatty acid doses and treatment duration. To choose fatty acid concentrations and time-points for study, dose- and time-response curves were generated to evaluate both myotube morphology and levels of phosphorylated and total AMPK, since it was the primary protein of interest. Dose-response curves (Figure 1) indicated that $0.75 \mathrm{mM}$ and $1.0 \mathrm{mM}$ palmitate treatments and 1.0mM DHA had high phospho-to-total AMPK ratios; however, there were few or no cells left on the plate after 24 hours with palmitate treatment in these concentrations, and the idea with the DHA treatment was not to bombard the cells with DHA, but to add a small amount of polyunsaturated fatty acids in comparison to the saturated fatty acids as done previously $(18,21,38,39,41)$. Therefore, we chose $0.5 \mathrm{mM}$ palmitate and $0.1 \mathrm{mM} \mathrm{DHA}$, as they provided the next greatest phosphorylation of AMPK without loss of cellular integrity and gave a polyunsaturated:saturated fatty acid ratio of 0.2 , which is similar to previous studies using a ratio of $0.25(21)$.

To determine the duration of treatment, we evaluated the myotube morphology and size. Since there were no apparent changes in morphology after 24 hours (Figure 2A), we focused on 48 and 96 hour time-points for measurement of myotube diameter (Figure 2B). Palmitate treatment decreased myotube diameter by $25 \%(\mathrm{p}=0.052)$ after 48 hours and over $90 \%(\mathrm{p}<0.001)$ after 96 hours versus control. However, DHA maintained myotube morphology and diameter; adding DHA to the palmitate treatment increased myotube diameter by almost half $(\mathrm{p}=0.004)$ after 48 hours and over 100\% ( $<<0.001)$ after 96 hours versus palmitate alone. Because the most dramatic change in myotube morphology and size without complete loss of palmitate cells occurred at 96 hours, we chose this time-point to conduct subsequent measurements. Furthermore, since a treatment effect on $\beta$-tubulin levels at timepoints longer than 24 hours was observed, all subsequent western blot measures were normalized to GAPDH protein expression because it did not demonstrate a time x treatment effect.

Palmitate-induced detriments to myotube morphology and size are attenuated by $\mathrm{DHA}$. To determine if maintenance of myotube morphology with DHA treatment was due to activation of the AMPK pathway, we measured phosphorylation of AMPK $\alpha$ on Thr172, which is required for its activation (40), and total AMPK protein expression (Figure $3 \mathrm{~A}$ ). Phospho-AMPK $\alpha^{\text {Thr172 }}$ 
levels were not significantly different between treatments, but addition of DHA to the palmitate treatment led to $106 \%$ higher $(\mathrm{p}=0.05)$ total AMPK levels than palmitate alone, which was associated with a 5.7-fold increase $(\mathrm{p}=0.032)$ in the AMPK ratio in palmitate versus control conditions.

To determine if the activation of AMPK with palmitate treatment was propagated downstream, we examined its cytosolic target, acetyl Co-A carboxylase (ACC) (Figure 3B). AMPK inhibits ACC through phosphorylation on Ser79, which reduces lipid synthesis and allows for fatty acyl-CoA entry into the mitochondria (43). While all fatty acid treatments led to increases in phospho-ACC ${ }^{\text {Ser79 }}$ levels, there were no significant changes between treatments or versus control. These data are consistent with the phospho-AMPK $\alpha^{\text {Thr172 }}$ data (Figure $3 \mathrm{~A}$ ). The total ACC levels mirrored its phosphorylated levels and were also no significantly different between treatments; therefore, the ACC ratio was also similar between treatments (Figure 3B).

Palmitate treatment increases intramyocellular lipid content of myotubes. Since AMPK is considered to be a regulator of lipid homeostasis in skeletal muscle (45), next we evaluated the intramyocellular lipid content with different fatty acid treatments. Myotubes were stained with Oil red O, which indicates the levels of all neutral lipids. There was a 400\% $(p<0.000)$ increase in auto fluorescence of Oil red $\mathrm{O}$ stained myotubes with palmitate treatment when normalized to average protein content per treatment. Intramyocellular lipid content returned to control levels in DHA-palmitate co-treated myotube cultures (Figure 4).

DHA maintains protein abundance of oxidative markers in palmitate-treated myotubes. Since AMPK is also known to activate transcription for long-term regulation of lipid homeostasis (20), the total protein expression of its nuclear target, PGC1 $\alpha$, was measured. PGC1 $\alpha$ is a transcription factor responsible for expression of genes involved in oxidative metabolism. Palmitate treatment decreased PGC1 $\alpha$ protein expression by $69 \%$ versus control $(p=0.4)$, although the addition of DHA to the palmitate treatment completely attenuated this effect by increasing its protein expression $165 \%(\mathrm{p}=0.017)$ versus palmitate treatment alone (Figure 5A). This suggests that DHA preserves oxidative metabolic capacity in palmitate-treated cells. To determine if the improvement in PGC1 $\alpha$ expression with DHA was matched downstream by an increase in oxidative metabolism, we measured CS activity as a marker of the tricarboxylic acid 
cycle and COX-IV protein expression as an indicator of the of the electron transport chain. We found disparate effects on these oxidative markers. CS activity demonstrated a small but significant $3 \%$ increase $(\mathrm{p}<0.05)$ with palmitate treatment versus all other conditions, and addition of DHA to palmitate had similar CS activity as control cells (Figure 5B). However, palmitate treatment led to a $34 \%$ decrease $(\mathrm{p}=0.297)$ in COX-IV protein expression, while addition of DHA returned COX-IV expression to control levels (Figure 5C).

DHA attenuates palmitate-induced detriments in the insulin signaling pathway. To determine if changes in intramyocellular lipid content and markers of oxidative metabolism with DHA treatment led to alterations in the insulin signaling pathway, the inhibitory serine phosphorylation site of the insulin receptor substrate (IRS) 1 was examined. All fatty acid treatments elevated $\mathrm{p}$-IRS-1 ${ }^{\text {Ser636/639 }}$ by 2 -3-fold, although these increases were not significant from each other or control conditions (Figure 6). Because changes were noted in markers of lipid content and oxidative metabolism with the different treatments, which were associated with disparate effects on myotube morphology and size, investigation of insulin signaling was continued further downstream of IRS-1 to examine activation of Akt, GSK3 $\beta$, and rpS6. The phosphorylation of Akt on Ser473 was measured because it is required for its activation (13), and previous research has demonstrated it to be decreased with palmitate treatment in skeletal muscle $(18,29,33)$. Although not statistically significant, Akt phosphorylation and total protein were decreased by at least one-third and phospho-GSK3 $\beta$ by almost half with palmitate treatment versus control conditions, while addition of DHA completely attenuated these decreases (Figure 7A\&B). Contrary to the Akt data, however, total GSK3 $\beta$ levels remained unchanged (Figure 7A\&C). The effects of DHA on palmitate treatment continued all the way downstream to rpS6; palmitate decreased phospho-rpS6 $6^{\text {Ser240/244 }}$ levels to approximately $25 \%$ of control, while addition of DHA increased its activation by 7 -fold $(\mathrm{p}=0.017)$ (Figure 8$)$.

To observe the responsiveness of the signaling pathway, myotubes were stimulated with $100 \mathrm{nM}$ insulin for 15 minutes, a dose and time consistent with previous literature performing immunoblotting (5) and chosen to elicit a maximal signaling response. Overall, DHA again attenuated the decrements of palmitate treatment (Figure 9). Phospho-Akt was reduced by half by palmitate treatment, although not statistically significant, and total Akt protein expression was only $\sim 25-45 \%$ of the other treatments $(\mathrm{p}<0.02)$. Activation of GSK3 $\beta$ was also decreased 55- 
$85 \%$ by palmitate $(\mathrm{p}<0.03)$. Addition of DHA attenuated all of these decreases to approximately $70 \%$ of control values $(\mathrm{p}<0.03)$. Together these data indicate a complete rescue of basal- and a partial but significant attenuation of insulin-stimulated- signaling by adding the omega-3 polyunsaturated fatty acid DHA to the saturated fatty acid palmitate treatment. 


\section{CHAPTER 5. DISCUSSION}

The central aim of this thesis was to determine if long term administration of $n-3$ PUFAs enhances FA oxidation and reduces intramyocellular lipid accumulation compared to palmitate treatment through activation of the AMPK signaling pathway in skeletal muscle cell culture. The central hypothesis was that long-term DHA treatment of $\mathrm{C}_{2} \mathrm{C}_{12}$ myotubes would activate the AMPK pathway to improve oxidative capacity, reduce intramyocellular lipid content, and enhance insulin signaling. The main finding of this thesis is that after 4 days of treatment in a cell culture model of a high fatty acid environment, DHA attenuated the negative effects of palmitate on myotube size and morphology, some measures of oxidative metabolism, intramyocellular lipid content, and insulin signaling independently of AMPK activation. Overall these data confirm previous findings $(6,8,18,21,36,39,41)$ that omega-3 polyunsaturated fatty acids have the ability to prevent detrimental effects of saturated fatty acids.

A most-striking initial finding of this research is that myotube morphology and size were markedly and differentially altered by palmitate and DHA. Long-term treatment of cells with palmitate altered the typical morphological properties of myotubes; after 2 days myotubes were significantly smaller in diameter than with either control or DHA conditions, and after 4 days very few myotubes remained and most cells lost adherence to the plate. However, this effect was completely attenuated by co-treatment with DHA, as this group demonstrated a $12 \%$ increase in diameter even over control cells after 4 days.

To determine if the changes in myotube morphology were associated with changes in protein expression and activation of signaling proteins involved in lipid metabolism, we measured AMPK phosphorylation and total protein expression. Contrary to our hypothesis, DHA does not appear to exert its positive effects through activation of AMPK since all fatty acid treatments led to non-significant 2-3-fold increases in phosphorylated AMPK. However, there was a significant difference in the AMPK ratio between treatments, which was due to decreased total AMPK levels in palmitate-treated cells. The total AMPK data are supported by previous findings that total AMPK $\alpha$ protein levels were decreased by approximately $60 \%$ after 5 months of high fat feeding in rodents. However, phospho-AMPK ${ }^{\text {Thr172 }}$ levels were also decreased (22), which is 
contrary to our data and could possibly reflect the differences between animal and cell culture models.

The high AMPK ratio in the palmitate treated cells indicates that most of the remaining total AMPK present in the cells was activated. Given the morphology of the cells treated with palmitate, it is most-likely that the myotubes were undergoing apoptosis and/or death and were trying to produce energy by activating the master energetic regulator that stimulates ATPproducing processes (44). While cell death was not measured, our lab has previously demonstrated that $0.75 \mathrm{mM}$ palmitate treatment of myotubes for 16 hours lead to a 7 -fold increase in DNA fragmentation versus control-treated cells (29), and the activation of AMPK via AICAR treatment in differentiating $\mathrm{C}_{2} \mathrm{C}_{12}$ myoblasts led to increased DNA fragmentation and caspase-3 cleavage (46). These data along with the morphological characteristics of the cells suggest that the palmitate-treated cells were undergoing apoptosis.

Moreover, addition of DHA to the palmitate treated cells maintained the AMPK phospho:total ratio near control levels, and the morphological and cell size data of these cells was similar to control-treated myotubes. Together these findings support that DHA did not differentially increase AMPK phosphorylation but was able to maintain the AMPK ratio through attenuation of the decrease in total AMPK and possibly contribute to the attenuation of cellular atrophy and death. Our phospho-AMPK data may be different from the findings of Liu et al. (22) because we were examining a more extreme model of atrophy/cell death than their animal model.

The cytosolic downstream target of AMPK, ACC, similarly demonstrated nonsignificant 2-4fold increases in phosphorylation but did not display decreased total ACC levels, leading to similar ratios of phosphorylated to total ACC in all conditions. These data suggest that ACCmediated fatty acid oxidation was not different between treatments and that lipid synthesis may also be similar because two of the primary cellular metabolic fates of long chain fatty acyl Co-A molecules are $\beta$-oxidation or conversion to diacylglycerol and triacylglycerol for storage (35).

To determine if the fatty acid treatments led to differential changes in lipid storage, intramyocellular lipid content was examined. Because activation of AMPK decreases expression of genes involved in lipid synthesis (3), an increase in the phosphorylated:total AMPK ratio suggests that intramyocellular lipid content should be decreased with palmitate treatment. This is not what the data indicated, as intramyocellular lipid content was substantially increased in the palmitate-treated cells versus the other conditions, which is consistent with our hypothesis. 
Pimenta et al. (30) also observed 2.5-to-3-fold increases in phosphorylation of AMPK and ACC after palmitate treatment, which was associated with approximately 3 -fold increases in intramyocellular lipids. Moreover, apart from measurements of AMPK activation, the conditions of obesity $(24,31)$ and high fat-feeding $(10,38)$ are shown to increase intramyocellular lipid content. These data indicate that although DHA was able to reduce accumulation of intramyocellular lipids when added to the palmitate treatment, this alteration was not through activation of the AMPK pathway. It is possible that the reduced intramyocellular lipid content in the control and both DHA treatments was due to an increase in lipid oxidation versus palmitate conditions, resulting in lower net lipid content versus palmitate-treated cells.

We hypothesized that addition of DHA to the palmitate treatment increases the ability of the cell to deal with the influx of fatty acids by improving oxidative metabolism; therefore, the transcription factor PGC1 $\alpha$ was examined. PGC1 $\alpha$ is located in the nucleus and promotes expression of genes involved in oxidative metabolism $(2,16,17,27)$. Addition of DHA to the palmitate treatment maintained PGC1 $\alpha$ near control levels, which indeed suggests that DHA may maintain palmitate-induced decreases in oxidative metabolism to improve utilization of intramyocellular lipids and attenuate cellular atrophy and/or death. In line with this, there are data to suggest a relationship between PGC1 $\alpha$ expression level and cell size. Sandri et al. (34) demonstrated a sharp decrease in PGC1 $\alpha$ mRNA expression in diabetes-induced atrophied muscle, which they suggested may be triggered by insulin resistance. They also showed that maintenance of PGC1 $\alpha$ levels conferred protection from muscle atrophy by inhibiting transcription of atrophy-related genes, which they noted may be an indirect effect of a PGC1 $\alpha$ mediated increase in mitochondrial content or $\beta$-oxidative metabolism (34). Our data support these findings and suggest that maintenance of PGC1 $\alpha$ and resulting differences in oxidative metabolism may contribute to cell size and morphology in a high fat environment.

One consideration that must be made when interpreting the results of this study deals with the apparent uncoupling between the AMPK ratio and the phosphorylation of ACC and protein expression of PGC1 $\alpha$, which would both be expected to increase with an increase in the AMPK ratio. The data of Suzuki et al. (40) may partially explain the disparate effects on the cytosolic and nuclear targets of AMPK in our study. They demonstrated that phosphorylation of Thr172 on the $\alpha 2$ subunit is critical for activity of AMPK and that the regulatory $\beta$ subunit determines its subcellular localization. Upon leptin stimulation of $\mathrm{C}_{2} \mathrm{C}_{12}$ myoblasts, the AMPK $\alpha 2 / \beta 1$ complex 
remained in the cytosol while the $\alpha 2 / \beta 2$ complex translocated to the nucleus after 1 hour, returned to the cytosol after 3 hours, and localized to both the nucleus and cytosol after 6 hours (40). Since both nuclear and cytosolic targets of AMPK rely on phosphorylation of $\alpha 2$ but were not affected similarly in our study, it is unlikely that a decrease in $\alpha 2$ could be solely responsible for the decrease in PGC1 $\alpha$ expression. It is possible that $\alpha 1$ levels could be decreased with palmitate treatment, as the antibody for total AMPK targeted both $\alpha$ subtypes, but this is also unlikely because $\alpha 1$ does not translocate to the nucleus (40) which is where the most detrimental effects occurred to AMPK substrates with palmitate treatment. Therefore, palmitate treatment could have altered both protein expression of the AMPK $\alpha 2$ and $\beta 2$ subunits, leading to a decrease in nuclear translocation of the complex and thus activation of transcription factors in the nucleus. This would not necessarily affect phosphorylation of ACC, as the $\beta 1$ subunit is primarily responsible for localizing the complex to the cytosol, and given the long time-period, the biphasic response of the $\alpha 2 / \beta 2$ complex would localize some of the remaining $\alpha 2 / \beta 2$ to the cytosol to phosphorylate ACC. Further examination of the effects of FA on the $\beta$ subunits are needed to clarify this possibility.

To determine if markers of oxidative metabolism were maintained similarly to PGC1 $\alpha$ content by addition of DHA to palmitate treatment, the activity of CS and protein expression of COX-IV were examined as markers of the tricarboxylic acid cycle and electron transport chain, respectively. Contrary to our hypothesis, DHA did not increase CS activity either alone or with palmitate treatment. Conversely, there was a small increase in CS activity with the palmitate treatment, although most-likely not enough to translate to a physiologically-significant increase in oxidative metabolism. This finding does go along with previous data demonstrating an increase in CS activity in skeletal muscle after high fat feeding (42) and in the muscle of obese animals (12). Ultimately, however, these data indicate that DHA did not rescue myotube morphology by increasing enzyme activity of the initial step of the tricarboxylic acid cycle. Alternatively, DHA did maintain COX-IV protein levels versus palmitate treatment alone. These data support the idea that maintenance of PGC1 $\alpha$ also maintains mitochondrial content in the myotubes (34), which would result in preservation of oxidative enzyme protein content instead of necessarily increasing enzyme activity to maintain oxidative capacity and ultimately myotube morphology. 
Furthermore, Muoio and colleagues (16) found that high-fat-induced insulin resistance in animals was associated with decreased expression of PGC1 $\alpha$ and accumulation of intramuscular acylcarnitines (from $\beta$-oxidation), while PGC1 $\alpha$ overexpression in myocytes favored formation of $\mathrm{CO}_{2}$ (complete fatty acid oxidation). They suggest that nutrient oversupply leads to an increase in lipid oxidation where the flux of $\beta$-oxidative by-products overcomes the capacity of the tricarboxylic acid cycle, resulting in incomplete fatty acid oxidation and accumulation of $\beta$ oxidative intermediates that may contribute to mitochondrial malfunction (16). Considering these findings, palmitate treatment may trigger a compensatory increase in CS activity as an attempt to improve complete lipid oxidation in light of increased $\beta$-oxidative flux without concomitant enhancement of downstream oxidative metabolism (i.e. COX-IV protein abundance) due to decreased PGC1 $\alpha$ expression. This is further supported by the finding that DHA maintained PGC1 $\alpha$ and attenuated all of these changes when added to palmitate treatment.

Muoio's group demonstrated that the decrease in PGC1 $\alpha$ expression in their high-fat-fed animals was associated with insulin resistance (16), and Sandri et al. noted that diabetes-related muscle atrophy may be triggered by insulin resistance (34). Moreover, there is a plethora of data showing that saturated fatty acids are detrimental to skeletal muscle (19) and contribute to the formation of insulin resistance $(19,25)$, while exposure to unsaturated fatty acids prevents, attenuates, or reverses insulin resistance induced by saturated fatty acids and overnutrition (1, 4, $8,19,23,25,28,32,38,39)$. Therefore, another aim of this thesis was to determine if DHA could attenuate the negative effects of palmitate on the insulin signaling pathway in this cell culture model of a high-fat environment. We examined phosphorylation of IRS-1 on serine $636 / 639$, which is inhibitory to the protein We examined phosphorylation of IRS-1 on serine $636 / 639$, which is inhibitory to the protein $\{$ Morino, $2005 \# 137\}$, and found that all fatty acid treatments led to 2-3-fold increases in phosphorylation, but without significant differences between treatments or compared to control. Since this measure did not offer much insight into the sensitivity of the insulin signaling pathway, we continued downstream of IRS-1 and measured protein expression and activation of three proteins in the insulin signaling pathway, protein kinase B (Akt), glycogen synthase kinase (GSK) 33, and ribosomal protein S6 (rpS6). Akt is a downstream substrate of IRS-1 that can directly inhibit GSK3 $\beta$, removing its inhibition of glycogen synthase, as well as indirectly activate $\mathrm{rpS} 6$ and promote synthesis of proteins involved in cell cycle progression (13). We also wanted to assess the responsiveness of the 
insulin signaling pathway after treatment with the different fatty acids but did not have means to perform radioisotopic labeling for glucose uptake or glycogen synthesis as functional outcome data; therefore, Akt and GSK3 $\beta$ activation and total protein levels after insulin stimulation were measured.

The palmitate-induced decrease in basal and insulin-stimulated Akt activation is consistent with previous research from our lab that demonstrated over $30 \%$ decreases in phospho-Akt ${ }^{\text {Ser } 473}$ and total Akt after treatment of myotubes with $0.75 \mathrm{mM}$ palmitate for 16 hours followed by 10 minutes of serum-stimulation (29). In addition, another group found an approximate 40\% decrease in phospho-Akt ${ }^{\mathrm{Ser} 43}$ upon insulin stimulation after 24 hours of palmitate treatment but not after treatment with oleate (a monounsaturated fatty acid) in cultured myotubes (33), highlighting the differential effects of unsaturated and saturated fatty acids on the insulin signaling pathway. More specifically to omega-3 polyunsaturated fatty acids, previous data demonstrated an enhancement of insulin signaling through Akt-mTOR-S6K-4EBP1 in steers fed with long-chain omega-3 fatty acids (9), and our finding of increased rpS6 phosphorylation with addition of DHA to the palmitate treatment expands this finding, as it is a substrate of S6K.

Together these data support the idea that the saturated fatty acid palmitate blunted growth and markers of oxidative metabolism, increased intramyocellular lipid content, and caused unresponsiveness to very high concentrations of insulin. However, the omega-3 polyunsaturated fatty acid DHA restored insulin responsiveness and cellular growth, as evidenced by the fact that addition of DHA attenuated the palmitate-induced changes in myotube morphology and size, intramyocellular lipid content, and PGC1 $\alpha$ and $\mathrm{COX}-\mathrm{IV}$ protein abundance, which was associated with improved basal and insulin-stimulated signaling. While it is not a completely novel finding that omega-3 fatty acids improve insulin signaling in skeletal muscle, as Storlien and colleagues demonstrated a positive effect of fish oil on systemic insulin sensitivity in 1987 (39), these data supports a novel theory for how long-chain omega-3 fatty acids may improve insulin signaling in skeletal muscle in a high fat environment. One of the most significant findings was that DHA maintained PGC1 $\alpha$ protein expression, and it is warranted to continue investigating whether this promotes oxidative metabolism and preserves mitochondrial mass and quality to prevent insulin resistance and cellular atrophy. 


\section{Limitations and Future Directives}

One limitation of this study is the lack of oxidative metabolic markers compared to the amount necessary to draw solid conclusions. Inclusion of a single transcription factor and only two markers in the entire oxidative pathway provides limited data with which to draw conclusions regarding the oxidative capacity of the cells after fatty acid treatment. This is especially significant in this data because we saw disparate effects on our oxidative markers with a slight palmitate-induced increase in CS activity and no change with addition of DHA, but decreased palmitate-induced protein abundance of PGC1 $\alpha$ and COX-IV, which was reversed with DHA. To strengthen these data, further examination of oxidative markers is required. These measurements should focus on both clarifying the differential effects on enzyme activity versus protein expression and identifying the functional outcome of these changes (i.e. lipid oxidation rates).

CS protein expression and COX activity should be measured to complement the measurement of its activity and protein abundance, respectively. The activity and protein expression of another tricarboxylic acid cycle enzyme, such as succinate dehydrogenase, and electron transport chain component, such as COX-I, could also be examined to provide a more comprehensive evaluation of the capacity of the tricarboxylic acid cycle and electron transport chain.

To identify if the maintenance of PGC1 $\alpha$ by DHA treatment alters "functional" outcomes of oxidative metabolism, mitochondrial content should be quantified to confirm that the protein expression of PGC1 $\alpha$ correlates to the mitochondrial content. This would nicely complement the markers of mitochondrial quality (CS and cytochrome c oxidase protein expressions and activities) to indicate overall mitochondrial capacity. Furthermore, lipid oxidation should also be measured as a functional outcome. The argument that fatty acid treatments increase lipid oxidation but without matching of tricarboxylic acid cycle and electron transport chain activity (26) suggests that measuring both incomplete and complete lipid oxidation is required. Previous data indicate that this can be accomplished by evaluating lipid incorporation into acid soluble metabolites (incomplete oxidation) and carbon dioxide (complete oxidation) $(7,16)$. Together these measurements would allow for a more complete examination of the oxidative metabolic capacity of myotubes after treatment with saturated and polyunsaturated fatty acids and allow for a more solid argument to be made with respect to their differential effects. 
Along the same lines as functional outcomes for oxidative metabolism, measuring more functional markers of insulin signaling would provide a clearer idea of the actual significance of the basal and insulin-stimulated Akt and GSK3 3 protein expressions. While there are data that demonstrate omega-3-related improvements in systemic insulin sensitivity in animal $(8,38,39)$ and human models (11) of insulin resistance, we cannot assume that these changes in insulin signaling in cell culture models holds equal value. Therefore, a functional measurement of glucose uptake, glycogen synthesis, and/or protein synthesis rate would strengthen these data.

As previously discussed, it is possible that palmitate treatment not only reduced AMPK $\alpha 2$ protein expression, but also protein expression of the $\beta 2$ subunit. Since the $\alpha 2 / \beta 2$ subunit translocates to the nucleus to activate and enhance protein expression of PGC1 $\alpha(14,20,40)$, the decrease of its abundance in the palmitate-treated cells could be due to loss of $\beta 2$ expression, as well. This possibility should be examined by measuring the total protein abundances of the $\beta 1$ and $\beta 2$ subunits by Western blotting. The data regarding phosphorylation (activation) of PGC1 $\alpha$ by AMPK is limited (14), and when good antibodies for these phosphorylation sites become commercially available, Western blotting could also be used to further examine if the phosphorylation of PGC1 $\alpha$ (indicating its activity) is altered similarly to its protein expression with the different fatty acid treatments.

Lastly, it is possible that the methods used in the cell culture model itself could be a limitation to this study. Recently Muoio's group published data suggesting that cell culture experiments examining the effects of fatty acid treatments on metabolic makers should include supplemental carnitine in the culture culture media (17). Carnitine is necessary for the formation of long chain acyl-carnitines from fatty acyl-CoA by carnitine palmitoyl transferase-1 in order to enter the mitochondria for $\beta$-oxidation (35). Since carnitine is synthesized in the liver, storage of carnitine in cultured skeletal muscles is very low which can restrict $\beta$-oxidation (17). Therefore, future studies examining the effects of saturated versus polyunsaturated fatty acids should include supplemental carnitine in the media in order to allow for physiologically normal $\beta$-oxidation to occur. This would ensure that any changes in $\beta$-oxidation with the different fatty acids would not be simply due to a decrease in necessary precursors for lipid oxidation. 


\section{Reference List}

1. Aas V, Rokling-Andersen MH, Kase ET, Thoresen GH, and Rustan AC. Eicosapentaenoic acid (20:5 n-3) increases fatty acid and glucose uptake in cultured human skeletal muscle cells. J Lipid Res 47: 366-374, 2006.

2. Benton CR, Nickerson JG, Lally J, Han XX, Holloway GP, Glatz JF, Luiken JJ, Graham TE, Heikkila JJ, and Bonen A. Modest PGC-1alpha overexpression in muscle in vivo is sufficient to increase insulin sensitivity and palmitate oxidation in subsarcolemmal, not intermyofibrillar, mitochondria. The Journal of biological chemistry 283: 4228-4240, 2008.

3. Canto C and Auwerx J. PGC-1alpha, SIRT1 and AMPK, an energy sensing network that controls energy expenditure. Current opinion in lipidology 20: 98-105, 2009.

4. D'Alessandro ME, Lombardo YB, and Chicco A. Effect of dietary fish oil on insulin sensitivity and metabolic fate of glucose in the skeletal muscle of normal rats. Ann Nutr Metab 46: 114-120, 2002.

5. Dimopoulos N, Watson M, Sakamoto K, and Hundal HS. Differential effects of palmitate and palmitoleate on insulin action and glucose utilization in rat L6 skeletal muscle cells. The Biochemical journal 399: 473-481, 2006.

6. Flachs P, Mohamed-Ali V, Horakova O, Rossmeisl M, Hosseinzadeh-Attar MJ, Hensler M, Ruzickova J, and Kopecky J. Polyunsaturated fatty acids of marine origin induce adiponectin in mice fed a high-fat diet. Diabetologia 49: 394-397, 2006.

7. Gaster M. Reduced lipid oxidation in myotubes established from obese and type 2 diabetic subjects. Biochemical and biophysical research communications 382: 766-770, 2009.

8. Ghafoorunissa, Ibrahim A, Rajkumar L, and Acharya V. Dietary (n-3) long chain polyunsaturated fatty acids prevent sucrose-induced insulin resistance in rats. J Nutr 135: 2634-2638, 2005.

9. Gingras AA, White PJ, Chouinard PY, Julien P, Davis TA, Dombrowski L, Couture Y, Dubreuil P, Myre A, Bergeron K, Marette A, and Thivierge MC. Long-chain omega-3 fatty acids regulate bovine whole-body protein metabolism by promoting muscle insulin signalling to the Akt-mTOR-S6K1 pathway and insulin sensitivity. $J$ Physiol 579: 269-284, 2007.

10. Guo ZK and Jensen MD. Accelerated intramyocellular triglyceride synthesis in skeletal muscle of high-fat-induced obese rats. Int J Obes Relat Metab Disord 27: 1014-1019, 2003.

11. Haugaard SB, Madsbad S, Hoy CE, and Vaag A. Dietary intervention increases n-3 long-chain polyunsaturated fatty acids in skeletal muscle membrane phospholipids of obese subjects. Implications for insulin sensitivity. Clin Endocrinol (Oxf) 64: 169-178, 2006.

12. Holloway GP, Benton CR, Mullen KL, Yoshida Y, Snook LA, Han XX, Glatz JF, Luiken JJ, Lally J, Dyck DJ, and Bonen A. In obese rat muscle transport of palmitate is increased and is channeled to triacylglycerol storage despite an increase in mitochondrial palmitate oxidation. American journal of physiology 296: E738-747, 2009.

13. Hresko RC and Mueckler M. mTOR.RICTOR is the Ser473 kinase for Akt/protein kinase B in 3T3-L1 adipocytes. The Journal of biological chemistry 280: 40406-40416, 2005. 
14. Jager S, Handschin C, St-Pierre J, and Spiegelman BM. AMP-activated protein kinase (AMPK) action in skeletal muscle via direct phosphorylation of PGC-1alpha. Proceedings of the National Academy of Sciences of the United States of America 104: 12017-12022, 2007.

15. Kinkel AD, Fernyhough ME, Helterline DL, Vierck JL, Oberg KS, Vance TJ, Hausman GJ, Hill RA, and Dodson MV. Oil red-O stains non-adipogenic cells: a precautionary note. Cytotechnology 46: 49-56, 2004.

16. Koves TR, Li P, An J, Akimoto T, Slentz D, Ilkayeva O, Dohm GL, Yan Z, Newgard CB, and Muoio DM. Peroxisome proliferator-activated receptor-gamma co-activator 1alpha-mediated metabolic remodeling of skeletal myocytes mimics exercise training and reverses lipid-induced mitochondrial inefficiency. The Journal of biological chemistry 280: 33588-33598, 2005.

17. Koves TR, Ussher JR, Noland RC, Slentz D, Mosedale M, Ilkayeva O, Bain J, Stevens R, Dyck JR, Newgard CB, Lopaschuk GD, and Muoio DM. Mitochondrial overload and incomplete fatty acid oxidation contribute to skeletal muscle insulin resistance. Cell metabolism 7: 45-56, 2008.

18. Le Foll C, Corporeau C, Le Guen V, Gouygou JP, Berge JP, and Delarue J. Longchain n-3 polyunsaturated fatty acids dissociate phosphorylation of Akt from phosphatidylinositol 3'-kinase activity in rats. American journal of physiology 292: E1223-1230, 2007.

19. Lee JS, Pinnamaneni SK, Eo SJ, Cho IH, Pyo JH, Kim CK, Sinclair AJ, Febbraio MA, and Watt MJ. Saturated, but not n-6 polyunsaturated, fatty acids induce insulin resistance: role of intramuscular accumulation of lipid metabolites. J Appl Physiol 100: 1467-1474, 2006.

20. Lee WJ, Kim M, Park HS, Kim HS, Jeon MJ, Oh KS, Koh EH, Won JC, Kim MS, Oh GT, Yoon M, Lee KU, and Park JY. AMPK activation increases fatty acid oxidation in skeletal muscle by activating PPARalpha and PGC-1. Biochemical and biophysical research communications 340: 291-295, 2006.

21. Liu S, Baracos VE, Quinney HA, and Clandinin MT. Dietary omega-3 and polyunsaturated fatty acids modify fatty acyl composition and insulin binding in skeletalmuscle sarcolemma. The Biochemical journal 299 ( Pt 3): 831-837, 1994.

22. Liu Y, Wan Q, Guan Q, Gao L, and Zhao J. High-fat diet feeding impairs both the expression and activity of AMPKa in rats' skeletal muscle. Biochemical and biophysical research communications 339: 701-707, 2006.

23. Lombardo YB, Hein G, and Chicco A. Metabolic syndrome: effects of n-3 PUFAs on a model of dyslipidemia, insulin resistance and adiposity. Lipids 42: 427-437, 2007.

24. Malenfant P, Tremblay A, Doucet E, Imbeault P, Simoneau JA, and Joanisse DR. Elevated intramyocellular lipid concentration in obese subjects is not reduced after diet and exercise training. American journal of physiology 280: E632-639, 2001.

25. Montell E, Turini M, Marotta M, Roberts M, Noe V, Ciudad CJ, Mace K, and Gomez-Foix AM. DAG accumulation from saturated fatty acids desensitizes insulin stimulation of glucose uptake in muscle cells. American journal of physiology 280: E229237, 2001.

26. Muoio DM and Koves TR. Lipid-induced metabolic dysfunction in skeletal muscle. Novartis Foundation symposium 286: 24-38; discussion 38-46, 162-163, 196-203, 2007. 
27. Muoio DM and Koves TR. Skeletal muscle adaptation to fatty acid depends on coordinated actions of the PPARs and PGC1 alpha: implications for metabolic disease. Applied physiology, nutrition, and metabolism $=$ Physiologie appliquee, nutrition et metabolisme 32: 874-883, 2007.

28. Mustad VA, Demichele S, Huang YS, Mika A, Lubbers N, Berthiaume N, Polakowski J, and Zinker B. Differential effects of n-3 polyunsaturated fatty acids on metabolic control and vascular reactivity in the type 2 diabetic ob/ob mouse. Metabolism 55: 1365-1374, 2006.

29. Peterson JM, Wang Y, Bryner RW, Williamson DL, and Alway SE. Bax signaling regulates palmitate-mediated apoptosis in $\mathrm{C}(2) \mathrm{C}(12)$ myotubes. American journal of physiology 295: E1307-1314, 2008.

30. Pimenta AS, Gaidhu MP, Habib S, So M, Fediuc S, Mirpourian M, Musheev M, Curi R, and Ceddia RB. Prolonged exposure to palmitate impairs fatty acid oxidation despite activation of AMP-activated protein kinase in skeletal muscle cells. Journal of cellular physiology 217: 478-485, 2008.

31. Roden M. Muscle triglycerides and mitochondrial function: possible mechanisms for the development of type 2 diabetes. International journal of obesity (2005) 29 Suppl 2: S111$115,2005$.

32. Rossi AS, Lombardo YB, Lacorte JM, Chicco AG, Rouault C, Slama G, and Rizkalla SW. Dietary fish oil positively regulates plasma leptin and adiponectin levels in sucrose-fed, insulin-resistant rats. Am J Physiol Regul Integr Comp Physiol 289: R486R494, 2005.

33. Sabin MA, Stewart CE, Crowne EC, Turner SJ, Hunt LP, Welsh GI, Grohmann MJ, Holly JM, and Shield JP. Fatty acid-induced defects in insulin signalling, in myotubes derived from children, are related to ceramide production from palmitate rather than the accumulation of intramyocellular lipid. Journal of cellular physiology 211: 244252, 2007.

34. Sandri M, Lin J, Handschin C, Yang W, Arany ZP, Lecker SH, Goldberg AL, and Spiegelman BM. PGC-1alpha protects skeletal muscle from atrophy by suppressing FoxO3 action and atrophy-specific gene transcription. Proceedings of the National Academy of Sciences of the United States of America 103: 16260-16265, 2006.

35. Schrauwen P. High-fat diet, muscular lipotoxicity and insulin resistance. Proc Nutr Soc 66: 33-41, 2007.

36. Simoncikova P, Wein S, Gasperikova D, Ukropec J, Certik M, Klimes I, and Sebokova E. Comparison of the extrapancreatic action of gamma-linolenic acid and n-3 PUFAs in the high fat diet-induced insulin resistance [corrected]. Endocr Regul 36: 143$149,2002$.

37. Stevenson EJ, Koncarevic A, Giresi PG, Jackman RW, and Kandarian SC. Transcriptional profile of a myotube starvation model of atrophy. J Appl Physiol 98: 1396-1406, 2005.

38. Storlien LH, Jenkins AB, Chisholm DJ, Pascoe WS, Khouri S, and Kraegen EW. Influence of dietary fat composition on development of insulin resistance in rats. Relationship to muscle triglyceride and omega-3 fatty acids in muscle phospholipid. Diabetes 40: 280-289, 1991. 
39. Storlien LH, Kraegen EW, Chisholm DJ, Ford GL, Bruce DG, and Pascoe WS. Fish oil prevents insulin resistance induced by high-fat feeding in rats. Science 237: 885-888, 1987.

40. Suzuki A, Okamoto S, Lee S, Saito K, Shiuchi T, and Minokoshi Y. Leptin stimulates fatty acid oxidation and peroxisome proliferator-activated receptor alpha gene expression in mouse $\mathrm{C} 2 \mathrm{C} 12$ myoblasts by changing the subcellular localization of the alpha2 form of AMP-activated protein kinase. Mol Cell Biol 27: 4317-4327, 2007.

41. Taouis M, Dagou C, Ster C, Durand G, Pinault M, and Delarue J. N-3

polyunsaturated fatty acids prevent the defect of insulin receptor signaling in muscle. American journal of physiology 282: E664-671, 2002.

42. Turner N, Bruce CR, Beale SM, Hoehn KL, So T, Rolph MS, and Cooney GJ.

Excess lipid availability increases mitochondrial fatty acid oxidative capacity in muscle: evidence against a role for reduced fatty acid oxidation in lipid-induced insulin resistance in rodents. Diabetes 56: 2085-2092, 2007.

43. Unger RH. Minireview: weapons of lean body mass destruction: the role of ectopic lipids in the metabolic syndrome. Endocrinology 144: 5159-5165, 2003.

44. Viollet B, Lantier L, Devin-Leclerc J, Hebrard S, Amouyal C, Mounier R, Foretz M, and Andreelli F. Targeting the AMPK pathway for the treatment of Type 2 diabetes. Front Biosci 14: 3380-3400, 2009.

45. Wang X, Zhou L, Li G, Luo T, Gu Y, Qian L, Fu X, Li F, Li J, and Luo M. Palmitate activates AMP-activated protein kinase and regulates insulin secretion from beta cells. Biochemical and biophysical research communications 352: 463-468, 2007.

46. Williamson DL, Butler DC, and Alway SE. AMPK inhibits myoblast differentiation through a PGC-1 \{alpha\}-dependent mechanism. American journal of physiology, 2009. 


\section{Figure Legends}

Figure 1. Dose-response curves for activation of AMPK following palmitate and cis-4, 7, 10, 13, 16, 19-docosahexaenoic acid (DHA) treatments. Cells were incubated in medium containing 2\% fetal calf serum, $2 \%$ bovine serum albumin, and the indicated fatty acid concentrations for 24 hours. Cells were harvested by scraping in 1X SDS-containing sample buffer, and samples were analyzed for phosphorylation of AMPK on Thr172 and total AMPK $\alpha$ and were normalized to $\beta$ tubulin. Representative Western blots are shown.

Figure 2. Myotube morphology and diameter are differentially altered with palmitate versus DHA treatment. Cells were incubated in medium containing $2 \%$ fetal calf serum, $2 \%$ bovine serum albumin, and either no fatty acids (Control), $0.5 \mathrm{mM}$ palmitate, $0.1 \mathrm{mM}$ cis-4, 7, 10, 13, 16, 19-docosahexaenoic acid (DHA), or 0.1mM DHA plus $0.5 \mathrm{mM}$ palmitate for 24,48 , or 96 hours. Fresh media was supplied after 48 hours. A) Images of myotubes after indicated treatment durations were collected via computer-integrated camera connected to a microscope at x10. B) Myotube diameter of treated cells. Six diameters per myotube from $\sim 10$ myotubes (per culture) from three wells per treatment condition that were treated for 48 and 96 hours with palmitate, DHA, DHA+palmitate, or no fatty acids. *Denotes $\mathrm{p} \leq 0.05$ versus other $48 \mathrm{~h}$ treatment conditions; ${ }^{\S}$ Denotes $\mathrm{p}<0.00$ versus other $96 \mathrm{~h}$ treatment conditions; $* *$ Denotes $\mathrm{p}<0.05$ versus $96 \mathrm{~h}$ control conditions.

Figure 3. DHA attenuates the reduced total AMPK $\alpha$ protein expression and the increased AMPK ratio observed with palmitate treatment. Cells were incubated in medium containing 2\% fetal calf serum, $2 \%$ bovine serum albumin, and either no fatty acids (Control), $0.5 \mathrm{mM}$ palmitate, $0.1 \mathrm{mM}$ DHA, or $0.1 \mathrm{mM}$ cis-4, 7, 10, 13, 16, 19-docosahexaenoic acid (DHA) plus $0.5 \mathrm{mM}$ palmitate for 96 hours with fresh media supplied after 48 hours. Cells were harvested by scraping in 1X SDS-containing sample buffer, and samples were analyzed for protein expression and normalized to glyceraldehydes-3-phosphate dehydrogenase (GAPDH) protein expression. Representative Western blots are shown. A) Phosphorylation of AMPK on Thr172 was not different between treatments, but co-treatment of DHA+Palmitate increased total AMPK $\alpha$ and attenuated the increased AMPK ratio observed with palmitate treatment. B) No significant differences were observed in phosphorylation of ACC on serine79, total ACC protein expression, 
or the ACC ratio. ${ }^{*}$ Denotes $\mathrm{p} \leq 0.05$ versus palmitate conditions for total AMPK $\alpha .{ }^{\S}$ Denotes $\mathrm{p}<0.05$ versus all other conditions for the AMPK ratio.

Figure 4. Palmitate treatment increases intramyocellular lipid content. Cells were incubated in medium containing $2 \%$ fetal calf serum, $2 \%$ bovine serum albumin, and either no fatty acids (Control), 0.5mM palmitate, 0.1mM cis-4, 7, 10, 13, 16, 19-docosahexaenoic acid (DHA), or $0.1 \mathrm{mM}$ DHA plus $0.5 \mathrm{mM}$ palmitate for 96 hours with fresh media supplied after 48 hours. After treatment, cells were treated with a 36\% Oil red O/triethyl phosphate solution that stains all neutral intramyocellular lipids and autofluoresces. Fluorescence was measured (excitation $485 \mathrm{~nm}$, emission $530 \mathrm{~nm}$ ) and normalized to average protein content per treatment. *Denotes $\mathrm{p}<0.0001$ versus all other conditions.

Figure 5. DHA maintains markers of oxidative metabolism in palmitate-treated cells. Cells were incubated in medium containing $2 \%$ fetal calf serum, $2 \%$ bovine serum albumin, and either no fatty acids (Control), $0.5 \mathrm{mM}$ palmitate, $0.1 \mathrm{mM}$ cis-4, 7, 10, 13, 16, 19-docosahexaenoic acid (DHA), or $0.1 \mathrm{mM}$ DHA plus $0.5 \mathrm{mM}$ palmitate for 96 hours with fresh media supplied after 48 hours. For analysis of protein expression, cells were harvested by scraping in 1X SDS-containing sample buffer and subjected to Western blotting. Expression was normalized to glyceraldehydes-3-phosphate dehydrogenase (GAPDH) protein expression. Representative Western blots are shown. A) Protein expression of peroxisome proliferator-activated receptor gamma coactivator $1 \alpha(\mathrm{PGC} 1 \alpha)$ is increased by adding DHA to palmitate treatment. *Denotes $\mathrm{p}<0.05$ versus palmitate condition. B) Citrate synthase (CS) activity. Treated cells were lysed with CellLytic M and mixed with acetyl coenzyme A, oxaloacetic acid, and 5-thio-2nitrobenzioc acid to spectrophotometrically measure CS activity by reading absorbance at $412 \mathrm{~nm} .{ }^{\S}$ Denotes $\mathrm{p}<0.05$ versus all other conditions. C) Cytochrome c oxidase subunit IV (COXIV) protein expression is not significantly altered with different fatty acid treatments.

Figure 6. Phosphorylation of IRS-1 is not different between palmitate and DHA treatments. Cells were incubated in medium containing $2 \%$ fetal calf serum, $2 \%$ bovine serum albumin, and either no fatty acids (Control), 0.5mM palmitate, $0.1 \mathrm{mM}$ cis-4, 7, 10, 13, 16, 19docosahexaenoic acid (DHA), or 0.1 $\mathrm{mM}$ DHA plus $0.5 \mathrm{mM}$ palmitate for 96 hours with fresh media supplied after 48 hours. Cells were harvested by scraping in 1X SDS-containing sample buffer and analyzed for protein expression of IRS-1 phosphorylation on serine636/639 and 
normalized to glyceraldehydes-3-phosphate dehydrogenase (GAPDH) protein expression. Representative Western blots are shown.

Figure 7. DHA treatment attenuates the palmitate-induced decrease in basal insulin signaling. Cells were incubated in medium containing $2 \%$ fetal calf serum, $2 \%$ bovine serum albumin, and either no fatty acids (Control), 0.5mM palmitate, $0.1 \mathrm{mM}$ cis-4, 7, 10, 13, 16, 19docosahexaenoic acid (DHA), or $0.1 \mathrm{mM}$ DHA plus $0.5 \mathrm{mM}$ palmitate for 96 hours with fresh media supplied after 48 hours. Cells were harvested by scraping in 1X SDS-containing sample buffer and analyzed for protein expression Akt and GSK3 $\beta$ normalized to glyceraldehydes-3phosphate dehydrogenase (GAPDH) protein expression. A) Representative Western blots for phospho-Akt ${ }^{\text {Ser473 }}$, phospho-GSK3 $\beta^{\text {Ser9 }}$, total Akt and GSK3 $\beta$. B) Basal phospho- and total Akt levels were not statistically different between treatments. C) Addition of DHA attenuated the decrease in basal phosphorylation of GSK3 $\beta^{\text {Ser9 }}$ seen with palmitate treatment, but total GSK3 $\beta$ expression was unchanged. *Denotes $p<0.05$ versus DHA conditions.

Figure 8. DHA treatment attenuates the palmitate-induced decrease in basal activation of ribosomal protein S6 (rpS6). Cells were incubated in medium containing 2\% fetal calf serum, $2 \%$ bovine serum albumin, and either no fatty acids (Control), $0.5 \mathrm{mM}$ palmitate, $0.1 \mathrm{mM}$ cis-4, 7, 10, 13, 16, 19-docosahexaenoic acid (DHA), or $0.1 \mathrm{mM}$ DHA plus $0.5 \mathrm{mM}$ palmitate for 96 hours with fresh media supplied after 48 hours. Cells were harvested by scraping in 1X SDScontaining sample buffer and analyzed for phosphorylation of rpS6 on Ser240/244 and normalized to glyceraldehydes-3-phosphate dehydrogenase (GAPDH) protein expression. Representative Western blots are shown. *Denotes $\mathrm{p}<0.05$ versus palmitate condition.

Figure 9. DHA treatment attenuates the palmitate-induced decrease in insulin-stimulated activation of signaling proteins. Cells were incubated in medium containing $2 \%$ fetal calf serum, $2 \%$ bovine serum albumin, and either no fatty acids (Control), $0.5 \mathrm{mM}$ palmitate, $0.1 \mathrm{mM}$ cis- 4,7 , 10, 13, 16, 19-docosahexaenoic acid (DHA), or 0.1 mM DHA plus $0.5 \mathrm{mM}$ palmitate for 96 hours with fresh media supplied after 48 hours. Cells were stimulated with $100 \mathrm{nM}$ insulin for 15 minutes then harvested by scraping in 1X SDS-containing sample buffer and analyzed for protein expression Akt and GSK3 $\beta$ normalized to glyceraldehydes-3-phosphate dehydrogenase (GAPDH) protein expression. A) Representative Western blots for phospho-Akt ${ }^{\mathrm{Ser} 733}$, phosphoGSK3 $\beta^{\text {Ser9 }}$, total Akt and GSK3 $\beta$ with insulin stimulation. B) DHA attenuates the palmitate- 
induced decrease in insulin-stimulated total Akt protein expression. ${ }^{*}$ Denotes $p<0.05$ versus all other conditions. C) DHA attenuates the palmitate-induced decrease in insulin-stimulated phosphorylation of GSK3 $\beta$ Ser9 and the ratio of phospho- to total GSK3 $\beta$. ${ }^{\dagger}$ Denotes $p<0.05$ versus all other conditions for $\mathrm{pGSK} 3 \beta$. ${ }^{\S}$ Denotes $\mathrm{p}<0.05$ versus all other conditions for the GSK ratio. 
Figure 1
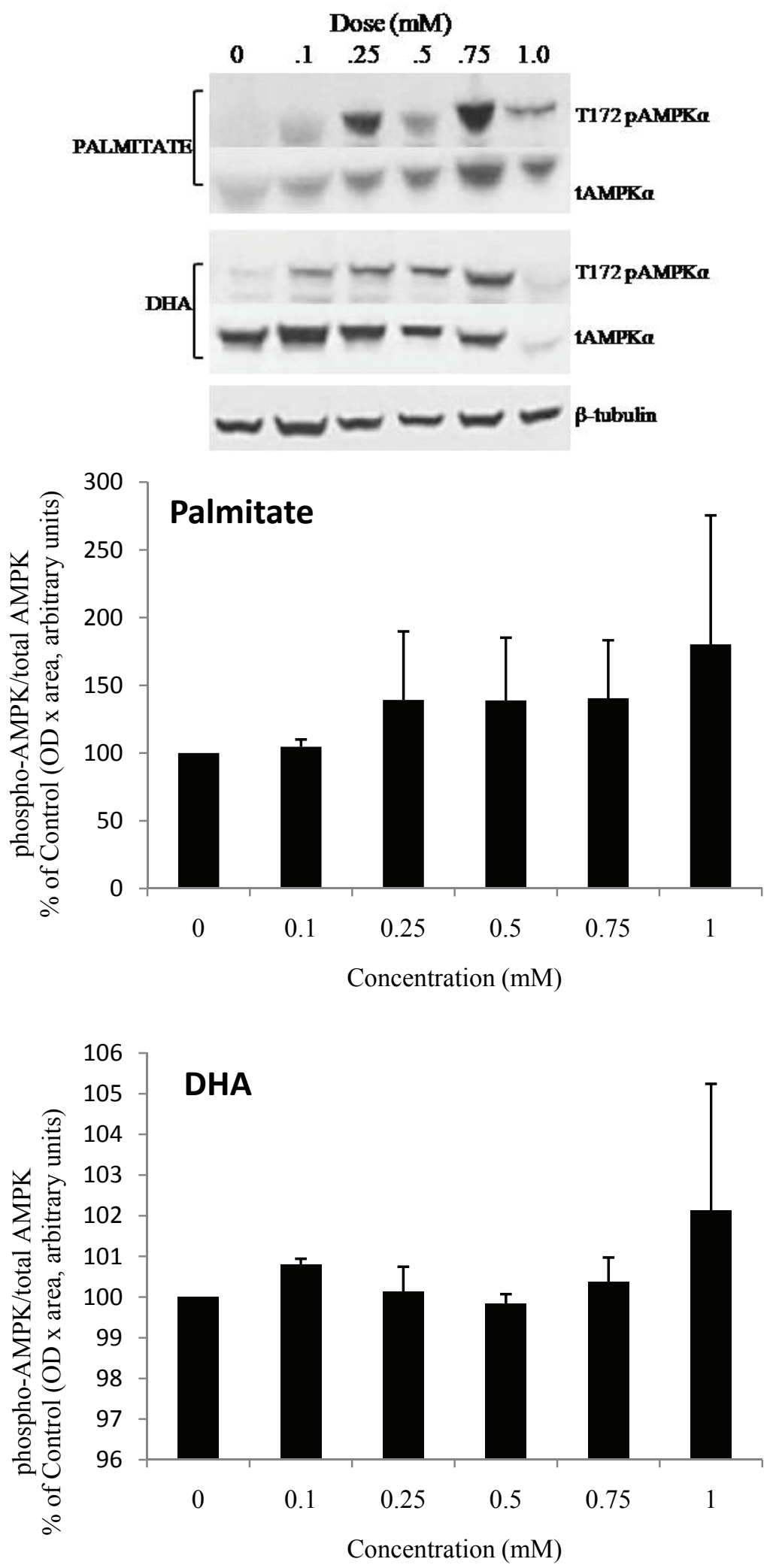
Figure 2

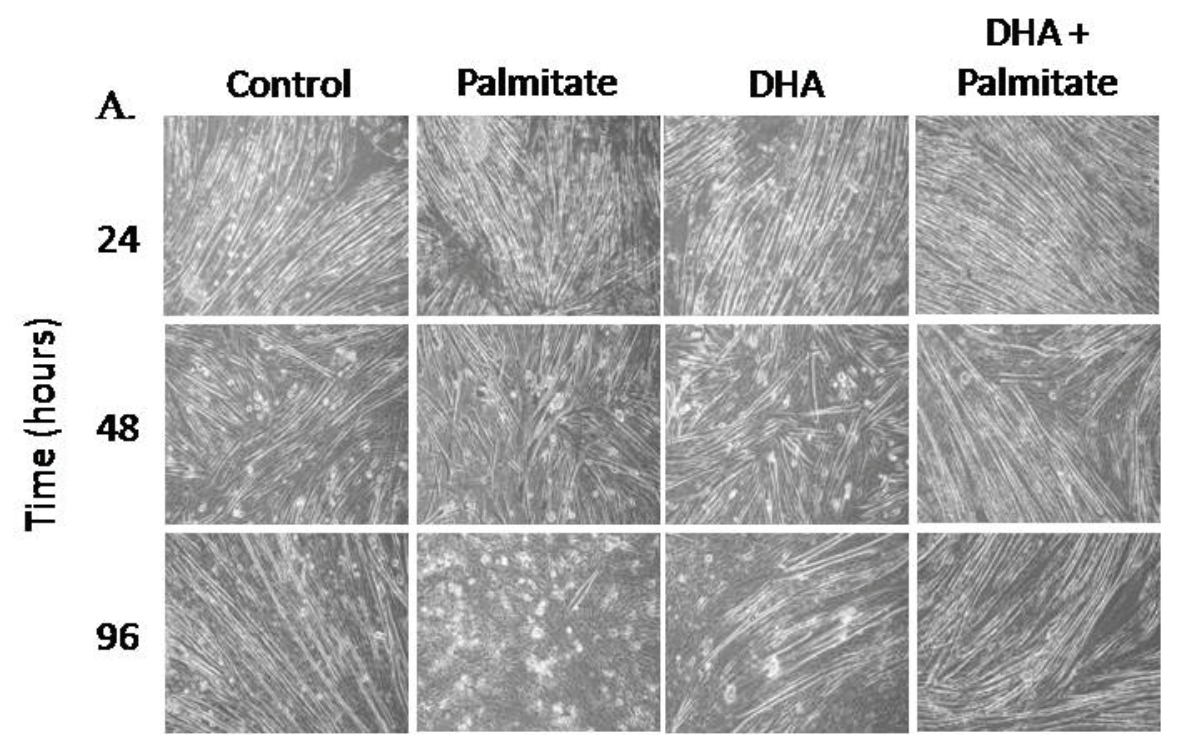

B.

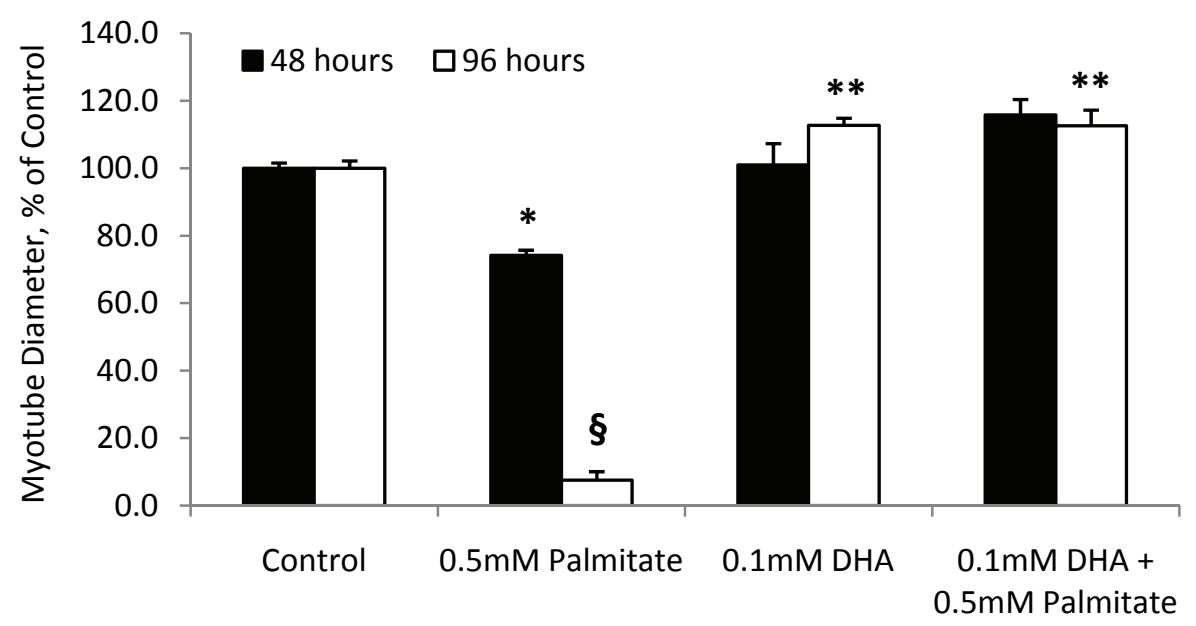


Figure 3
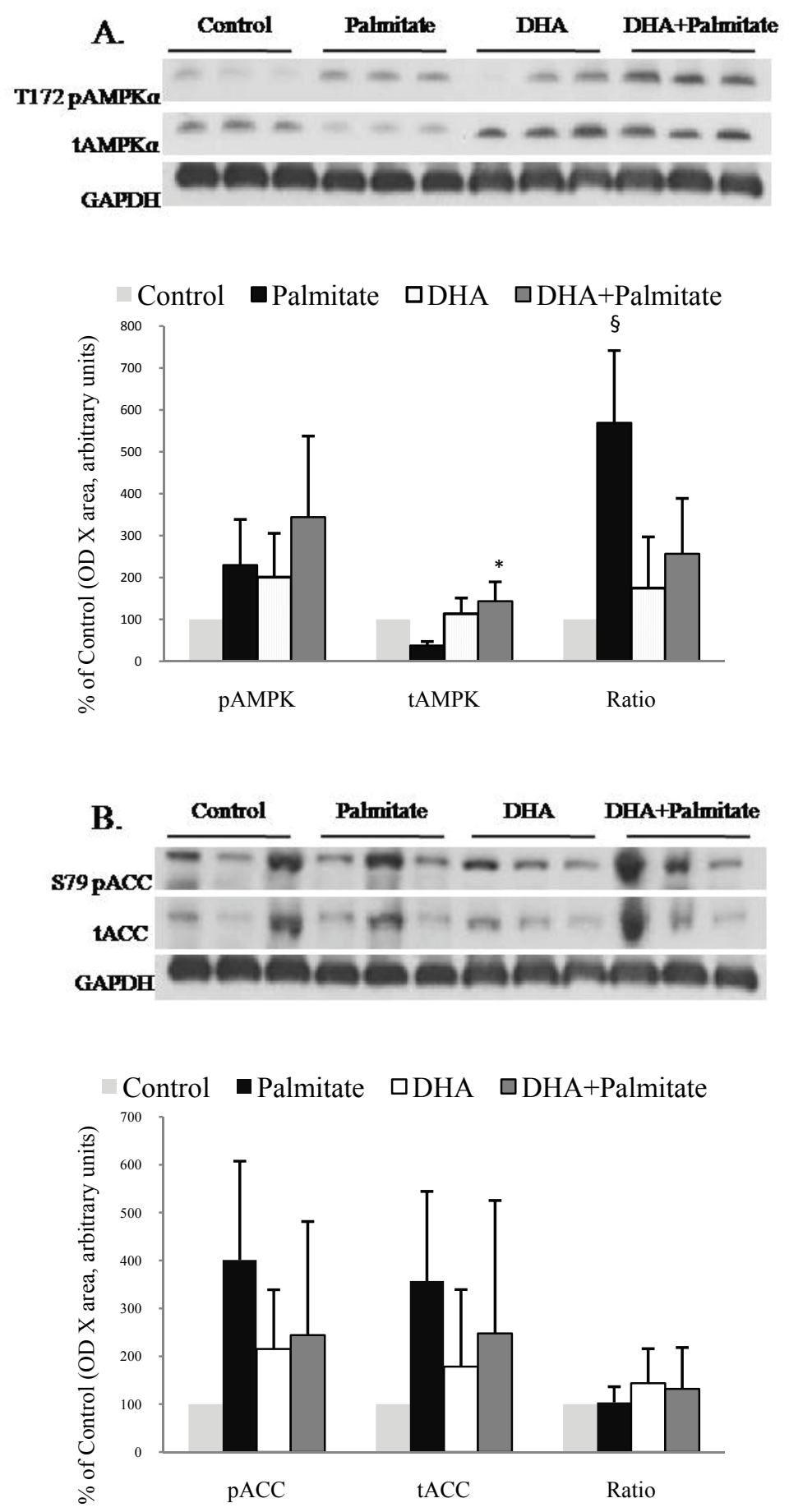
Figure 4

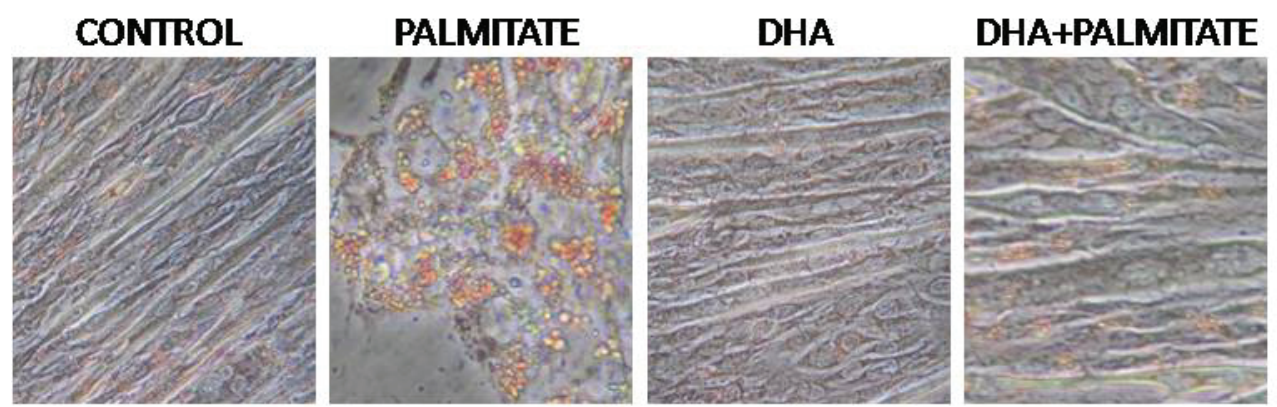

Control -Palmitate $\square$ DHA $\square$ DHA+Palmitate

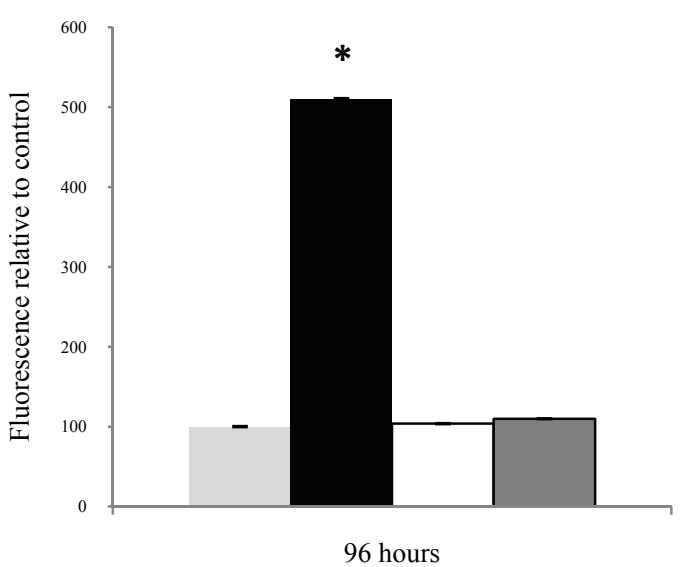




\section{Figure 5}
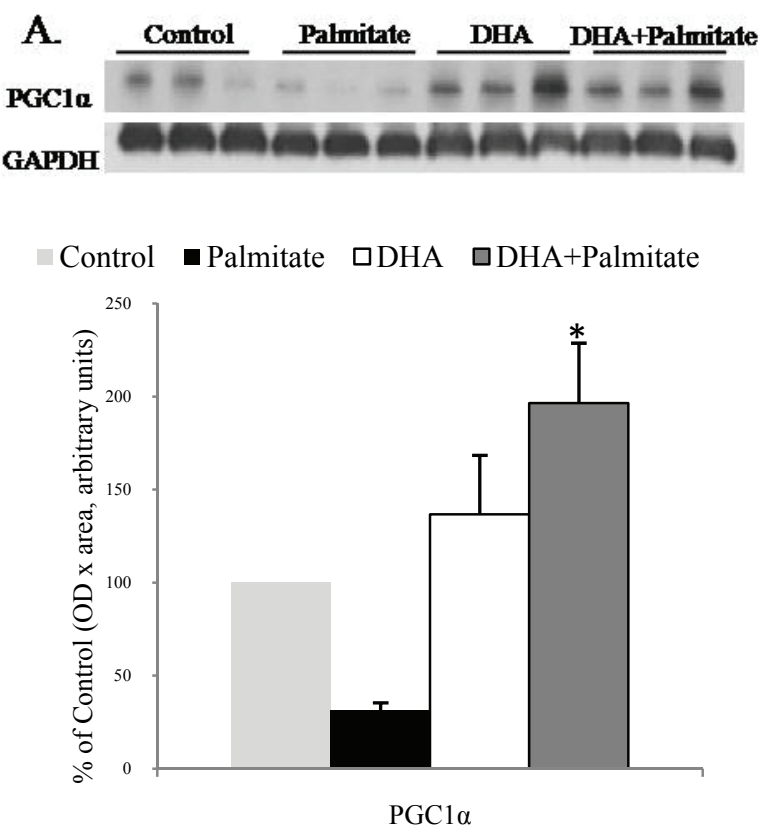

B.

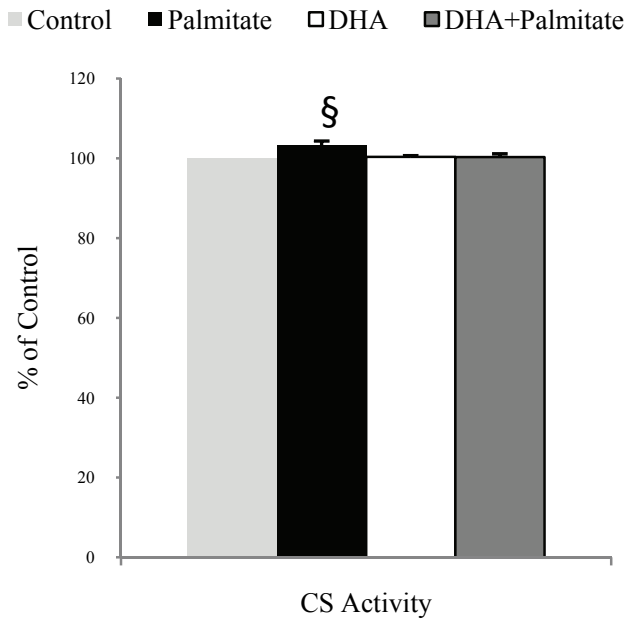


Figure 5
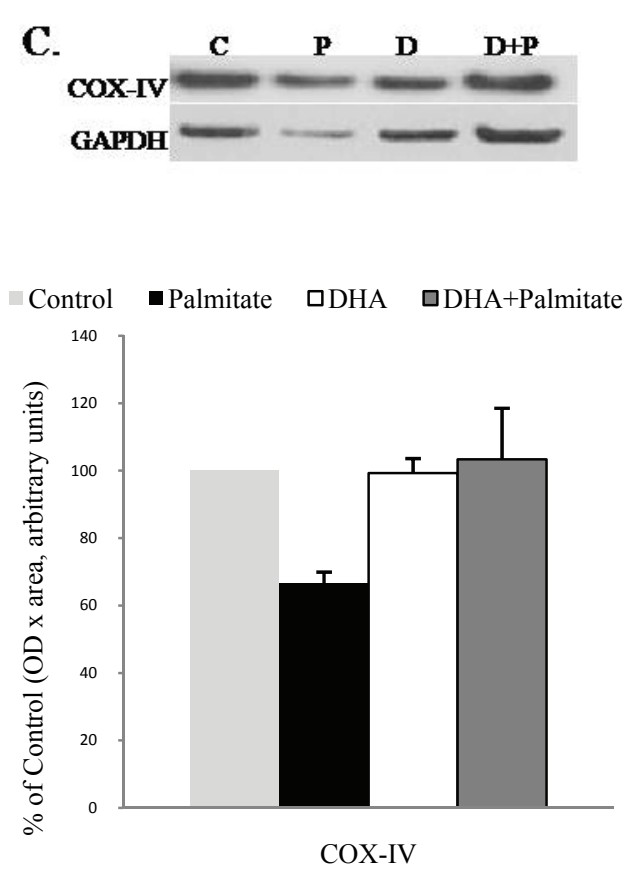
Figure 6

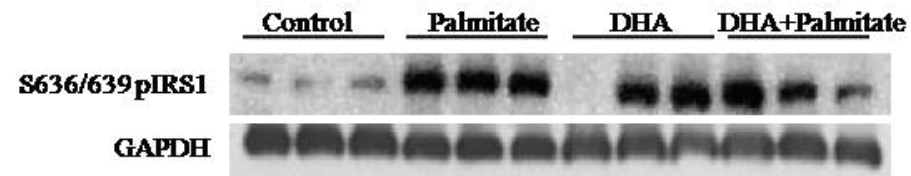

$\square$ Control $\square$ Palmitate $\square$ DHA $\square$ DHA+Palmitate

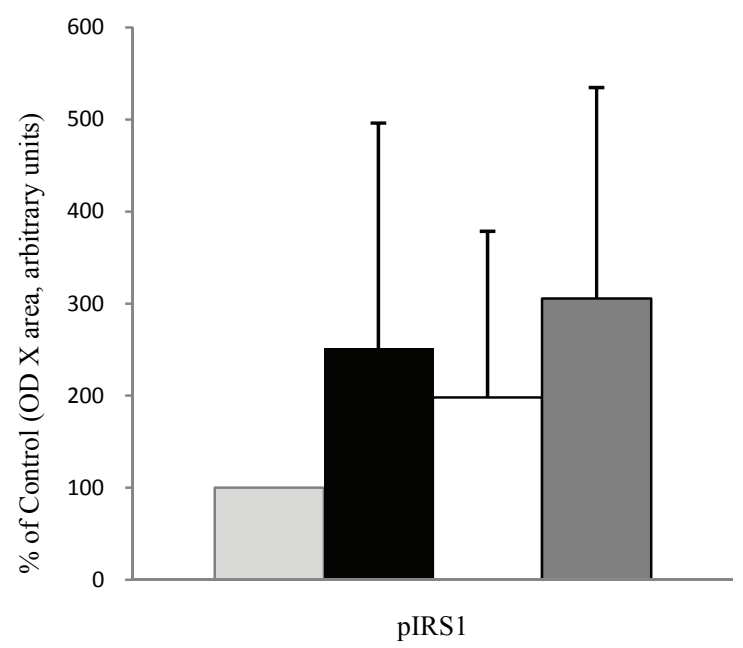


Figure 7

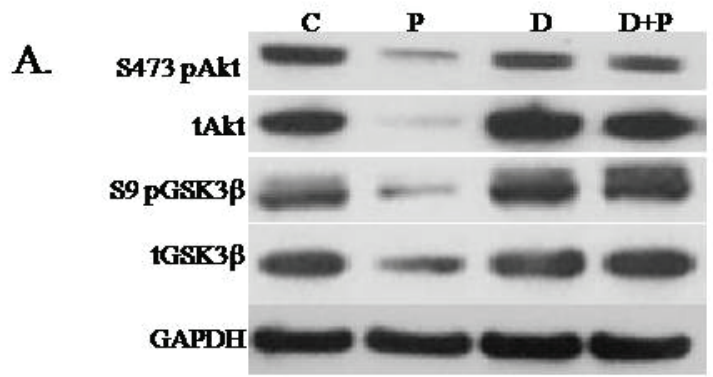

B.

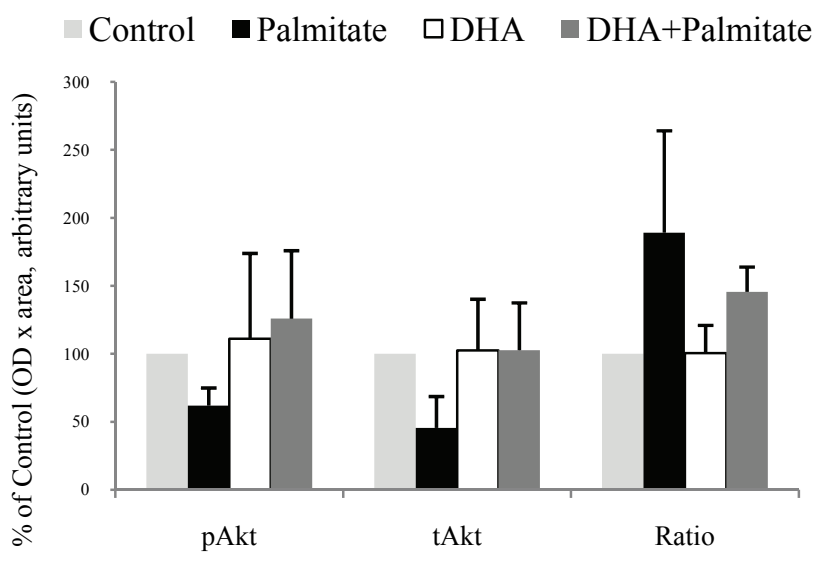

C.

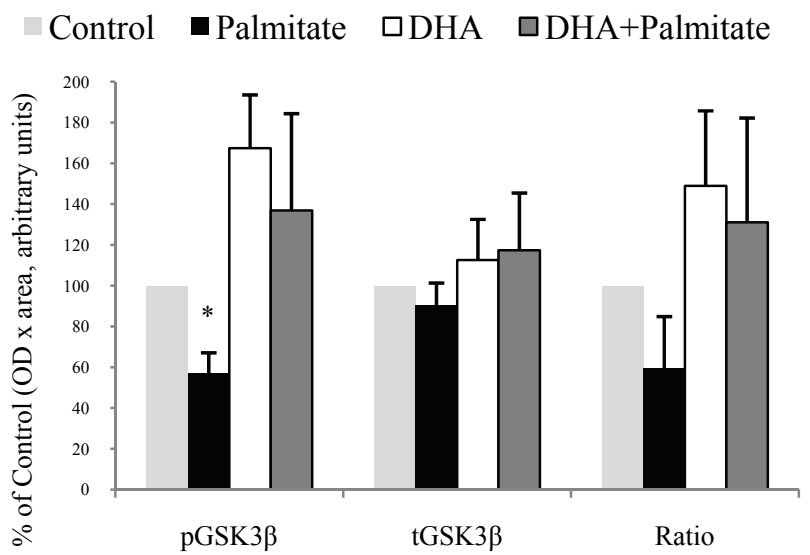




\section{Figure 8}
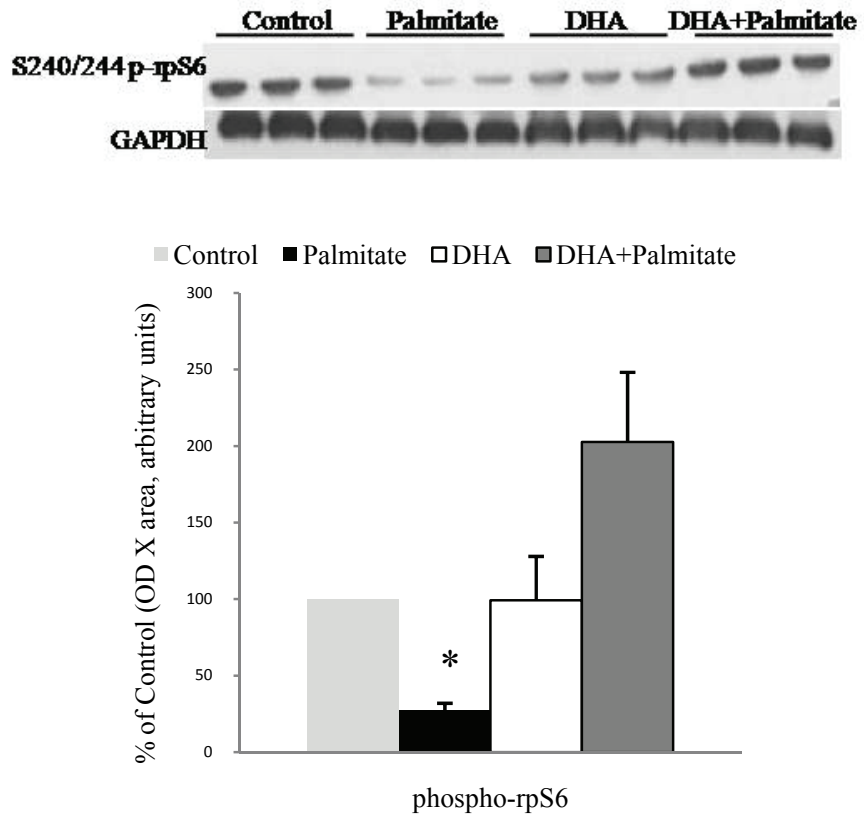


\section{Figure 9}

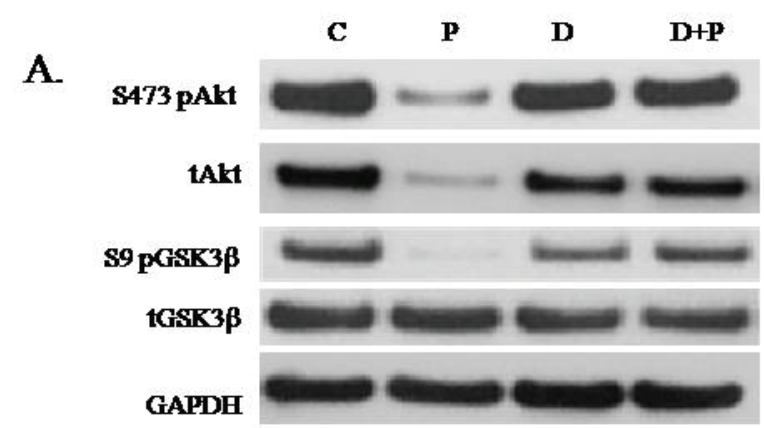

B.

Control $\square$ Palmitate $\square \mathrm{DHA} \square \mathrm{DHA}+$ Palmitate

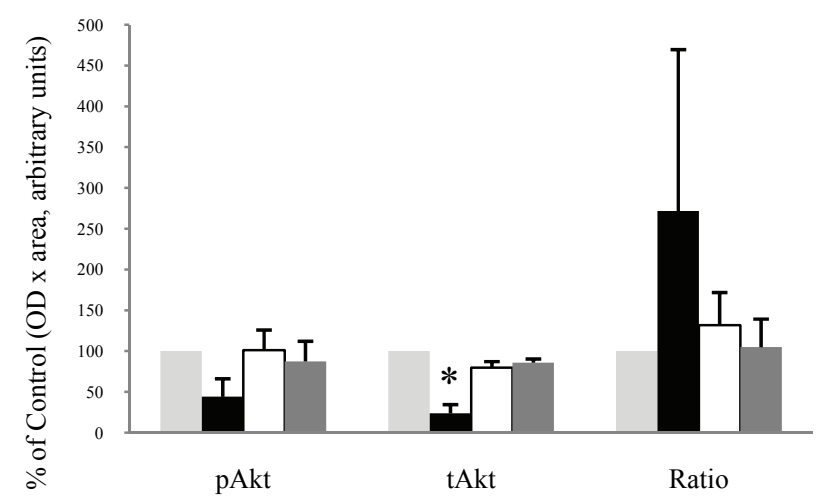

C.

Control $\square$ Palmitate $\square \mathrm{DHA} \square \mathrm{DHA}+$ Palmitate

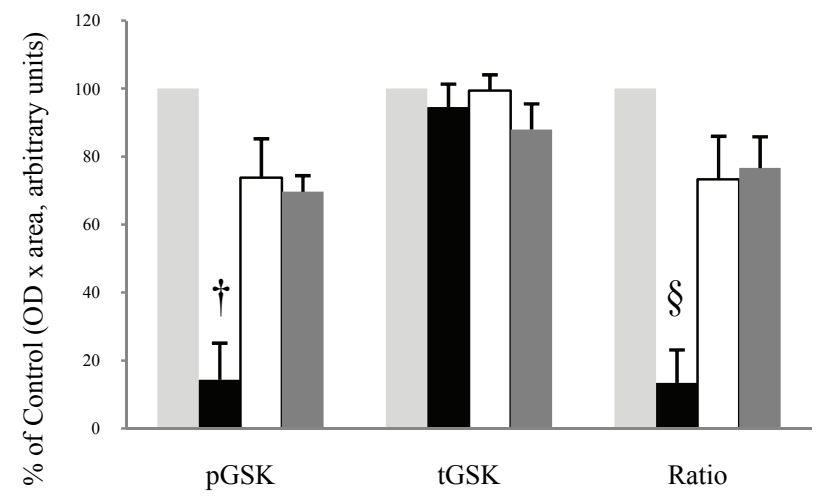

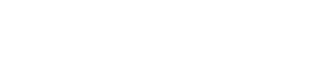

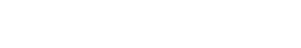
Department, email=John
Hagen@mail 